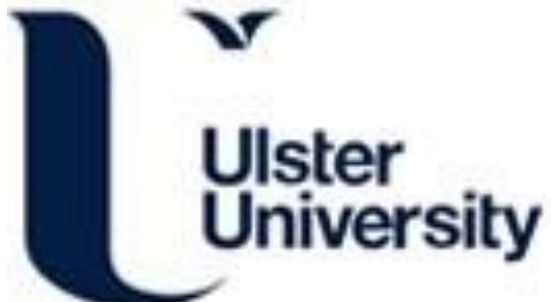

\section{Inflammation, insulin signaling and cognitive function in aged APP/PS1 mice.}

Denver, P., English, A., \& McClean, P. (2018). Inflammation, insulin signaling and cognitive function in aged APP/PS1 mice. Brain, Behavior, and Immunity, 70, 423-434. https://doi.org/10.1016/j.bbi.2018.03.032

Link to publication record in Ulster University Research Portal

\section{Published in:}

Brain, Behavior, and Immunity

Publication Status:

Published (in print/issue): 31/05/2018

DOI:

10.1016/j.bbi.2018.03.032

\section{Document Version}

Author Accepted version

\section{General rights}

Copyright for the publications made accessible via Ulster University's Research Portal is retained by the author(s) and / or other copyright owners and it is a condition of accessing these publications that users recognise and abide by the legal requirements associated with these rights.

\section{Take down policy}

The Research Portal is Ulster University's institutional repository that provides access to Ulster's research outputs. Every effort has been made to ensure that content in the Research Portal does not infringe any person's rights, or applicable UK laws. If you discover content in the Research Portal that you believe breaches copyright or violates any law, please contact pure-support@ulster.ac.uk. 
Behavior, and Immunity

Elsevier Editorial System(tm) for Brain,

Manuscript Draft

Manuscript Number: BBI-D-17-00762R2

Title: Inflammation, insulin signaling and cognitive function in aged APP/PS1 mice

Article Type: Full Length Article

Keywords: Alzheimer's disease; aging; neuroinflammation; insulin signaling; cognitive function; learning; memory; insulin sensitivity; cytokines

Corresponding Author: Dr. Paul A Denver, PhD

Corresponding Author's Institution: UCLA

First Author: Paul A Denver, PhD

Order of Authors: Paul A Denver, PhD; Andrew English; Paula L McClean, PhD

Abstract: Cognitive dysfunction and neuroinflammation are typical in Alzheimer's disease (AD), but are also associated with normal aging, albeit less severely. Insulin resistance in the brain has been demonstrated in $\mathrm{AD}$ patients and is thought to be involved in $\mathrm{AD}$ pathophysiology. Using 15-18 month-old APP/PS1 mice, this study measured peripheral and central insulin signaling and sensitivity, inflammatory markers in brain and plasma and oxidative stress and synapse density in the brain. Novel object recognition, Morris water maze and reversal water maze tasks were performed to assess cognitive function in aged APP/PS1 mice and wild type littermates. Glucose tolerance and insulin sensitivity were similar in APP/PS1 mice and wild type controls, however IRS-1 pSer616 was increased in cortex and dentate gyrus of APP/PS1 mice. Recognition and spatial memory was impaired in both APP/PS1 and wild type mice, however learning impairments were apparent in APP/PS1 mice. Expression of GLP-1 receptor, ERK2, IKK, mTOR, PKC $\theta, \mathrm{NF}-\mathrm{kB} 1$ and TLR4 was similar between aged APP/PS1 mice and age-matched wild types. Compared to age-matched wild type mice, IFNY and IL-4 were increased in brains of APP/PS1 mice. These results suggest that normal aging may be associated with enhanced neuroinflammation, oxidative stress, and cognitive decline, however distinctions are apparent in the brain of APP/PS1 mice in terms of inflammation and insulin signaling and in certain cognitive domains. Demarcation of pathological events that distinguish AD from normal aging will allow for improvements in diagnostic tools and the development of more effective therapeutics. 


\section{University of California, Los Angeles \\ Department of Neurology \\ 710 Westwood Plaza, Los Angeles, CA, 90095 \\ West Los Angeles VA Healthcare Center \\ 11301 Wilshire Boulevard, Los Angeles, CA 90073 \\ Tel: +1 (310) 478-3711 ext. 42171 \\ Email: pdenver@mednet.ucla.edu}

Professor Carmine M. Pariante, Editor-in-Chief, Brain, Behavior, and Immunity

Professor of Biological Psychiatry and NIHR Senior Investigator Award,

Stress, Psychiatry and Immunology Lab,

Institute of Psychiatry, Psychology and Neuroscience,

King's College London,

The Maurice Wohl Clinical Neuroscience Institute,

Cutcombe Road, London SE5 9RT

Dear Professor Pariante,

$17^{\text {th }}$ March 2018

On behalf of the authors, we are grateful for the thorough evaluation of our manuscript and the additional comments raised by the Reviewers and Editors. These have been very helpful and constructive. We have further revised our manuscript according to the points raised and we believe it has been strengthened as a result. Please see our responses to Reviewer's comments in a point-by-point fashion below.

We very much hope that you will consider our revised manuscript acceptable for publication in Brain, Behavior and Immunity.

Yours sincerely,

Dr Paul Denver 
Inflammation, insulin signaling and cognitive function in aged APP/PS1 mice. (BBI-D17-00762) 


\section{Highlights}

- Peripheral insulin sensitivity and glucose tolerance in aged APP/PS1 mice is comparable to wild-type.

- Recognition and spatial memory is impaired in aged wild-type and APP/PS1 mice.

- Spatial learning is impaired in aged APP/PS1 mice, compared to age-matched controls.

- IRS-1 pSer ${ }^{616}$ and astrocytes are elevated in brains of aged APP/PS1 mice compared to controls

- IFN $\gamma$, IL-1 $1 \beta$ and IL-4 are elevated in brains of APP/PS1 mice compared to agematched controls 
Inflammation, insulin signaling and cognitive function in aged APP/PS1 mice. (BBI-D17-00762R1)

\section{Reviewer \#2}

The explanations offered by the authors are adequate.

Thank you to the reviewer for acknowledging our previous response to reviewers' comments as adequate.

\section{$\underline{\text { Reviewer \#3 }}$}

While the reviewers generally recognize the new and interesting contributions to knowledge provided by this paper several specific deficiencies are identified. In response the authors have added sections to the paper with additional references to address these deficiencies. In particular reviewers have indicated that young cohorts of wild type and transgenic mice should have been included in the study. The authors acknowledge this but cite previously published work to provide support for their speculative assertions that synaptophysin staining may be generally reduced in brains of aged wild type mice in their experiments.

Where it was possible to do so the authors have responded well to comments made by the reviewers by including additional data, figures, text and citations. This includes additional details of data analysis in the statistics section and the addition of Figure 7. The authors acknowledge that their future studies should include the younger age cohorts, more discrete studies including regional brain areas and examining changes in microglia.

As with most large studies that employ multiple sensitive techniques it will always be possible to identify interesting additions that might have been included if time and funds were available however the reality is that these are often limited.

Thank you to the reviewer for their comments and for their appreciation for the limitations that were acknowledged in our previous response to reviewers' comments and in the manuscript itself. As noted by this reviewer, we added data, analysis, text and citations that we hope helps support our conclusions.

\section{Reviewer \#4}

In the revision, the authors have addressed several of the issues raised with the initial reviews. However, one major issue that remains is the absence of young cohort of WT and APP/PS1 mice. This absence is very significant and, apparently, can not be addressed by the authors.

Because there is some value in the aged WT vs APP/PS1 comparison, the entire manuscript should be completely restructured, streamlined, and focused solely on this comparison. The extremely limited data of young WT mice is a distraction, not an addition to the aged mice data. Data interpretation and discussion should also be limited to the contributions of the APP/PS1 genotype to differences between the aged WT and APP/PS1 animals.

Thank you to the reviewer for these helpful comments. The authors agree that our limited young data distracts from the aged data and detracts from the overall story of the manuscript, however, we feel that this young data is nevertheless of value here. We suggest that removing the young data from the 
main figures and condensing it into one supplementary figure may adequately address these concerns, while allowing the young data to be included in the article as supportive to the aged data, rather than as part of the main narrative. To this end, we removed the young data from figures 5 and 6 , we added one supplementary figure consisting of 4 panels and made adjustments to the text in the following sections of the manuscript to reflect these changes:

- Abstract

- Results; 3.1.4 Peripheral insulin sensitivity and glucose tolerance and inflammatory and insulin signaling gene expression in brains of aged APP/PS1 mice

- Results; 3.1.5 Cytokine levels in brains of aged APP/PS1 mice

- Discussion

The authors feel that these changes have improved the manuscript and reiterate our thanks to the reviewer for their insight. However, should the reviewer and/or the editor feel that our response was inadequate and would prefer if the young data was removed entirely, then we would be happy to oblige and remove it. 


\title{
Inflammation, insulin signaling and cognitive function in aged
}

\author{
APP/PS1 mice \\ Paul Denver ${ }^{\mathrm{a}, 1}$, Andrew English ${ }^{\mathrm{b}}$ and Paula L McClean ${ }^{\mathrm{b}}$ \\ ${ }^{a, 1}$ Centre for Molecular Biosciences, University of Ulster, Coleraine, Northern Ireland \\ ${ }^{b}$ Northern Ireland Centre for Stratified Medicine, Clinical, Translational and Research Innovation Centre (C- \\ TRIC), University of Ulster, Derry Londonderry, Northern Ireland
}

\begin{abstract}
: 243 words
Main text: 4,491 words
\end{abstract}

Figures: 7

Supplementary Figures: 1

Corresponding author: Paul Denver,

West Los Angeles VA Healthcare Center,

11301 Wilshire Boulevard, Los Angeles, CA 90073

Email address: pdenver@mednet.ucla.edu

Telephone: 1 (310) 478-3711 ext. 42171

${ }^{1}$ Present affiliations: Greater Los Angeles Veterans Affairs Healthcare System; West Los Angeles Medical Center and Dept. of Neurology, University of California, Los Angeles, CA, USA 


\begin{abstract}
Cognitive dysfunction and neuroinflammation are typical in Alzheimer's disease (AD), but are also associated with normal aging, albeit less severely. Insulin resistance in the brain has been demonstrated in AD patients and is thought to be involved in AD pathophysiology. Using 15-18 month-old APP/PS1 mice, this study measured peripheral and central insulin signaling and sensitivity, inflammatory markers in brain and plasma and oxidative stress and synapse density in the brain. Novel object recognition, Morris water maze and reversal water maze tasks were performed to assess cognitive function in aged APP/PS1 mice and wild type littermates. Glucose tolerance and insulin sensitivity were similar in APP/PS1 mice and wild type controls, however IRS-1 pSer $^{616}$ was increased in cortex and dentate gyrus of APP/PS1 mice. Recognition and spatial memory was impaired in both APP/PS1 and wild type mice, however learning impairments were apparent in APP/PS1 mice. Expression of GLP-1 receptor, ERK2, IKK $\beta$, mTOR, PKC $\theta, \mathrm{NF}-\kappa \mathrm{B} 1$ and TLR4 was similar between aged APP/PS1 mice and age-matched wild types. Compared to age-matched wild type mice, IFN $\gamma$ and IL-4 were increased in brains of APP/PS1 mice. These results suggest that normal aging may be associated with enhanced neuroinflammation, oxidative stress, and cognitive decline, however distinctions are apparent in the brain of APP/PS1 mice in terms of inflammation and insulin signaling and in certain cognitive domains. Demarcation of pathological events that distinguish $\mathrm{AD}$ from normal aging will allow for improvements in diagnostic tools and the development of more effective therapeutics.
\end{abstract}


Keywords: Alzheimer's disease; aging; neuroinflammation; insulin signalling; cognitive function; learning; memory; insulin sensitivity; cytokines

\begin{abstract}
Abbreviations: A $\boldsymbol{\beta}$ Amyloid- $\beta$ AD Alzheimer's disease ERK2 extracellular signal-regulated kinase 2 IKK $\beta$ Inhibitor of NF- $\mathrm{BB}$ kinase $\beta$ IRS-1 pSer $^{616}$ Insulin receptor substrate-1 phosphorylated at serine residue 616 MAPK mitogen-activated protein kinase mTOR mechanistic target of rapamycin MWM Morris water maze ORT Novel object recognition task PKC Protein kinase C RI Recognition index RWM Reversal water maze TLR4 Tolllike receptor 4
\end{abstract}

\title{
1 Introduction
}

As healthcare improves around the world, life expectancy continues to rise (1). Accordingly, the past 25 years have seen a dramatic increase in disorders associated with aging, including neurological diseases such as Alzheimer's disease (AD) (1), for which advancing age is the principal risk factor (2).

Many clinical and neuropathological features of AD parallel the normal progression of aging, making differentiation between normal brain aging and early-stage AD difficult. Generally, it can be said that healthy aging is associated with moderate decline in some cognitive abilities, whilst AD is characterized by severe deterioration of the same cognitive domains, with additional progressive decline of further cognitive functions, such that the patient's daily life is adversely affected to a severe degree (3). In $\mathrm{AD}$, amyloid- $\beta$ (A $\beta$ ) accumulates into progressively larger fibrils, which become deposited as insoluble plaques in the brain parenchyma (4). Accumulating evidence suggests that the presence of $A \beta$ fibrils and plaques is not uncommon in the brains of non-demented, cognitively healthy older people $(5,6)$. Several studies have also shown that $A \beta$ deposition does not correlate with 
cognitive impairment in elderly cohorts (6), highlighting the variability of age-related cognitive decline and suggesting that $\mathrm{A} \beta$ per se does not directly influence cognitive function.

Profound inflammation is evident in $\mathrm{AD}$ brain (7), primarily mediated by microglia and astrocytes $(8,9)$. Activated microglia and astrocytes phagocytose $\mathrm{A} \beta$ oligomers and fibrils, degrade $A \beta$ plaques and reduce amyloid burden $(10,11)$. However, sustained microglial activation and unresolved inflammation in the brain is harmful to neurons and synapses and promotes chronic dysregulation of glial cells and subsequent deterioration of brain structure and function $(12,13)$. Inflammation in the brain increases with age (14) and several studies have shown elevated levels of inflammatory cytokines in the brains of aged rodents $(15,16)$. In the context of $\mathrm{AD}$, primed microglia respond more readily to $\mathrm{A} \beta$, producing increased levels of cytokines that exert direct toxic effects on neurons and at synapses (17).

Insulin resistance has been demonstrated in postmortem brain tissue from $\mathrm{AD}$ patients and those with mild cognitive impairment, in the absence of diabetes and irrespective of ApoE- $\varepsilon 4$ status (18). Furthermore, IRS-1 $\operatorname{pSer}^{616}$ was identified as a putative biomarker of brain insulin resistance in $\mathrm{AD}$ and was found to correlate positively with $\mathrm{A} \beta$ oligomer levels and negatively with cognitive function (18). Additionally, Bomfim et al. (19) demonstrated increased levels of IRS-1 pSer $^{616}$ in the hippocampus of 13 month-old APP/PS1 mice. Other studies have also demonstrated impaired neuronal insulin signaling in $\mathrm{AD}$ brain and in response to $\mathrm{A} \beta$ oligomer challenge $(20,21)$.

This study sought to determine differences in learning and memory, oxidative stress, glucose tolerance, central and peripheral insulin sensitivity between 15-18 month old wild type and age-matched APP/PS1 mice. Using novel object recognition and Morris water maze tasks, cognitive function was measured in aged wild type and APP/PS1 mice. Systemic 
insulin sensitivity and glucose tolerance were compared between groups. Brain levels of A $\beta$, GFAP, 8-oxoguanine, IRS-1 $\operatorname{pSer}^{616}$ and synaptophysin were measured by immunohistochemistry. Additionally inflammatory and insulin signalling associated genes, GLP-1R, IKK $\beta$, ERK2, mTOR, NF-кB1, PKC $\theta$, and TLR4 and inflammatory cytokines (IFN $\gamma$, IL-10, IL-1 $\beta$, IL-12p70, IL-2, IL-4, IL-5, IL-6 and KC/GRO (CXCL1)) were assessed in brain tissue from aged APP/PS1 and wild type mice to delineate pathological changes from those associated with 'normal' aging.

\section{Materials and Methods}

\subsubsection{Animals}

Male $\mathrm{APP}_{\mathrm{swe}} / \mathrm{PS}_{\Delta \mathrm{e} 9}(\mathrm{APP} / \mathrm{PS} 1)$ mice with a $\mathrm{C} 57 \mathrm{Bl} / 6 \mathrm{~J}$ background were bred with wild type C57B1/6J females at the Biomedical and Behavioural Research Unit at Ulster University in Coleraine. Offspring were ear punched and positivity for the $\mathrm{APP}_{\text {swe }} / \mathrm{PS} 1_{\Delta \mathrm{e} 9}$ transgene, or lack thereof was confirmed by polymerase chain reaction, using primers specific for the APP sequence of the APP/PS1 construct (Forward "GAATTCCGACATGACTCAGG", Reverse: "GTTCTGCTGCATCTTGGACA"). Offspring males heterozygous for the APP ${ }_{\text {swe }} / \mathrm{PS}_{\triangle \mathrm{e} 9}$ transgenic construct were then age-matched with wild type littermates, not expressing the transgene, which were used as controls. Both groups of mice were caged individually and allowed access to food and water ad libitum. Animals were maintained on a 12:12 light-dark cycle (lights on at 08:00, lights off at 20:00), within a temperature-controlled room (T: $21.5^{\circ} \mathrm{C} \pm 1^{\circ} \mathrm{C}$ ). All tests were performed during the light cycle. All experiments were designed, analyzed and reported in accordance with ARRIVE guidelines. Experiments were licensed according to UK Home Office regulations (UK Animals Scientific Procedures Act 1986) and associated guidelines (EU Directive 2010/63/EU). C57B1/6 mice were derived from a colony maintained in the Biomedical and Behavioural Research Unit at Ulster University in Coleraine. 


\subsubsection{Glucose tolerance and insulin sensitivity tests}

After an overnight fasting period, APP/PS1 mice and age-matched wild types received an i.p. injection of glucose $(18 \mathrm{mmol} / \mathrm{kg} \mathrm{bw})$ in $0.9 \% \mathrm{NaCl}$ or insulin $(0.25 \mu \mathrm{M} / \mathrm{g})$. Blood glucose was measured at $0,15,30$ and 60 minutes following glucose or insulin injection using a hand-held Ascencia Contour blood glucose meter (Bayer Health Care).

\subsubsection{Behavioural Assessment}

Mice were assessed in the ORT, as described previously (22). Briefly, mice were subjected to a 10 minute acquisition period, with two identical objects, followed by a 3 hour retention period and a 10 minute test phase, which involved replacing one of the objects with a novel object. A recognition index (RI) was calculated for each object, defined as amount of time spent exploring object A or B over the total time spent exploring both objects $\mathrm{x} 100$ (tA or $\mathrm{tB} /(\mathrm{tA}+\mathrm{tB}) \mathrm{x} 100)$

Following ORT, mice were assessed in the Morris water maze (MWM) (22). The acquisition training phase consisted of 4 x 90 second trials per day, for 4 consecutive days, followed by a probe trial on the fifth day. The day after the probe trial, mice were subjected to reversal water maze (RWM), wherein the escape platform was moved from the southwest to northwest quadrant. There were 4 trials per day, for 4 consecutive days, followed by a reversal probe trial on day 5 .

\subsubsection{Immunohistochemistry}

Following sacrifice, animals were perfused with PBS and brains excised. One hemisphere was fixed in $4 \%$ paraformaldehyde and the other was frozen in liquid nitrogen. Hemi-brains for histology were then transferred to $30 \%$ sucrose and $40 \mu \mathrm{m}$ coronal sections were cut 
using a cryostat (Leica Microsystems). One section in every 6 was collected sequentially and stored at $-20^{\circ} \mathrm{C}$. Staining was performed for $\mathrm{A} \beta$, GFAP, 8-oxoguanine, IRS-1 $\mathrm{pSer}^{616}$ and synaptophysin. All sections were incubated in $\mathrm{H}_{2} \mathrm{O}_{2}$ and permeabilized using Triton X. For 8oxoguanine, sections were incubated at $37^{\circ} \mathrm{C}$ for 30 minutes with $2 \mathrm{M}$ hydrochloric acid, followed by $0.1 \mathrm{M}$ borax (Sigma Aldrich) for 10 minutes. Blocking with 1.5\%-10\% normal serum was performed prior to incubation with anti-A $\beta$ (1:200; Invitrogen; 71-5800) antiGFAP (1:250; Merck Millipore; MAB3402), anti-8-oxoguanine (1:250; Merck Millipore; MAB3560), anti-IRS-1 pSer ${ }^{616}$ (1:200; Invitrogen; 44-550G) or anti-synaptophysin (1:200; Abcam; ab7837) antibodies overnight at $4^{\circ} \mathrm{C}$. Sections were then incubated with secondary antibodies and visualized using Vectastain Elite and SG substrate (Vector Laboratories). Percentage area stained in each image was quantified using a multi threshold plug-in within Image J (NIH, Bethesda, USA) in a blinded manner.

\subsubsection{Quantitative polymerase chain reaction ( $q P C R$ )}

RNA was extracted from brain tissue using RNeasy Lipid Tissue Mini Kit (Qiagen) according to manufacturer's instructions. For cDNA synthesis, transcriptor First Strand cDNA synthesis kit (Roche Diagnostics) was used using 500 ng of RNA per sample. Realtime PCR reactions were composed of; $5 \mu$ of PCR MasterMix (Roche Diagnostics), $1 \mu \mathrm{l}$ (10 $\mathrm{pM} / \mu \mathrm{l})$ gene-specific probes, $3 \mu \mathrm{l}$ of RNase free water and $1 \mu \mathrm{l}(25 \mathrm{ng})$ of template cDNA. Gene-specific probes (Roche Diagnostics) were as follows: GLP-1R (Glplr), IKK $\beta$ (Ikbkb), ERK2 (Mapk1), mTOR (Mtor), NF-kB1 (Nfkb1), PKC (Prkcq) and TLR4 (Tlr4). Quantitative PCR was performed on Lightcycler 480 system (Roche Diagnostics), and 
quantified on accompanying software package (Roche, Lightcycler 480 software, v1.5). Gene expression changes were calculated using Delta Delta CT mathematical model (23).

\subsubsection{Meso Scale Discovery multi-array}

Whole hemi-brains were homogenized under liquid nitrogen, followed by addition of $10 \mathrm{ml} / \mathrm{g}$ of lysis buffer (1 mM EDTA in PBS supplemented with protease inhibitor cocktail). Samples were centrifuged at $14,000 \mathrm{G}$ for $20 \mathrm{~min}$ at $4^{\circ} \mathrm{C}$ and supernatant was removed and added to Meso Scale Discovery $\left(\mathrm{MSD}^{\circledR}\right)$ plate. Bradford protein assay was performed to measure protein content and data were normalized to the total amount of protein present in each sample. Levels of IFN $\gamma$, IL1 $\beta$, IL-2, IL-4, IL-5, IL-6, IL-10, IL-12p70, TNF- $\alpha$ and KC/GRO (CXCL1) were quantified in brain and plasma using MSD $^{\circledR}$ Multi-spot Assay Proinflammatory panel 1 kit (Rockville, MD, USA) according to manufacturer's instructions.

\subsubsection{Statistical Analysis}

Data were analyzed using Graphpad Prism (v6.0h). Differences were deemed to be significant if $p \leq 0.05$. Data are expressed as means \pm SEM. Tests included one-way or twoway ANOVA and unpaired Student's $t$ tests. Data heterogenity was tested and, where variance was significant, appropriate non-parametric tests were used. Corrections for multiple comparisons were performed using appropriate post-hoc tests. Linear relationships between two variables were measured by Pearson's correlation analysis.

\section{Results}

\subsubsection{Spatial learning is impaired in aged APP/PS1 mice}

During the acquisition phase of the MWM, escape latency significantly decreased over time $(p<0.0001)$, as expected, and was also significantly greater overall in APP/PS1 mice (Fig. 
$1 \mathrm{~A} ; p=0.0264)$. However, post-hoc analysis indicated that average escape latency was not significantly different between aged wild type and APP/PS1 mice on any of the training days (Fig. 1A). In the probe trial, time spent in each quadrant by wild type mice was not significantly different (Fig. 1D). Similarly, APP/PS1 mice spent a similar amount of time swimming in all 4 quadrants in the probe trial and although significant variation in the time spent in each quadrant was detected $(p=0.0174)$, post-hoc analysis showed that time spent in the target quadrant by APP/PS1 mice was not significantly different from any other quadrant (Fig. 1G). In the acquisition phase of the RWM, escape latency decreased over time (Fig. 1B; $p=0.0009$ ) and was also significantly affected by genotype (Fig. 1B; $p=0.0020$ ). Post-hoc analysis revealed that average escape latency was significantly greater in APP/PS1 mice, compared to wild types on days $2(p<0.05), 3(p<0.01)$ and $4(p<0.05$; Fig. 1B).

In the reversal probe trial, time spent in each of the quadrants by wild types (Fig. 1E) or APP/PS1 (Fig. 1H) mice did not differ significantly

\subsubsection{Recognition memory is impaired in aged APP/PS1 and wild type mice}

In the acquisition phase of the ORT, recognition indices for the identical objects were not significantly different in 15-18 month old APP/PS1 or wild type mice (Fig. 1C). In the test phase, recognition index for the novel object was not significantly different from the familiar in the aged APP/PS1 mice or the age-matched control group (Fig. 1F).

\subsubsection{Immunohistochemistry}

3.1.3.1 A $\beta$ deposition is ubiquitous in brains of aged APP/PS1 mice 


\subsubsection{IRS-1 $\mathrm{pSer}^{616}$ is elevated in brains of aged APP/PS1 mice}

Representative micrographs illustrate increased levels of IRS-1 $\mathrm{pSer}^{616}$ in the cerebral cortex (Fig. 2M) and dentate gyrus (Fig. 2N) of APP/PS1 mice, compared to age-matched wild types (Fig. 2I and J). Although distribution of IRS-1 pSer $^{616}$ staining was similar between groups in both brain regions, staining intensity was greater in APP/PS1 mice (Fig. 2O) compared to wild types (Fig. $2 \mathrm{~K}$ ). As such, quantification showed that IRS-1 pSer ${ }^{616}$ was significantly greater in the cortex (Fig. $2 \mathrm{~L} ; p=0.0303$ ) and dentate gyrus (Fig. $2 \mathrm{P} ; p=0.0429$ ) of aged APP/PS1 mice compared to wild type controls. Pearson's correlation analysis identified negative correlations between recognition index for the novel object in ORT and IRS-1 pSer ${ }^{616}$ immunopositivity in the cortex (Fig. 7A) dentate gyrus (Fig. 7B) of wild type and APP/PS1 mice. Although the negative correlation between cortical IRS-1 $\mathrm{pSer}^{616}$ staining and ORT recognition index in APP/PS1 approached significance (Fig. 7A; $r=-0.7744$, $p=0.0706$ ) the negative trends between IRS- 1 pSer $^{616}$ staining and ORT recognition index remained insignificant in both brain regions of both genotypes.

\subsubsection{Oxidative stress is comparable in brains of aged APP/PS1 and wild type mice}

Representative micrographs shown in Fig. 3A-C and E-G illustrate the similarity in oxidative stress levels between the brains of aged APP/PS1 mice and wild type controls. Quantitative 
analysis demonstrated that 8-oxoguanine immunopositivity was not significantly different in the cortex (Fig. 3D) or the dentate gyrus (Fig. 3H) of APP/PS1 mice compared to agematched wild type controls.

\subsubsection{Astrocytes are elevated in brains of aged APP/PS1 mice}

Representative micrographs illustrate increased levels of GFAP-positive astrocytes in the cerebral cortex (Fig. 3I and J) and dentate gyrus (Fig. 3M and N) of aged APP/PS1 mice compared to wild type controls. Quantitative analysis revealed a significant increase in GFAP immunopositivity in the cortex (Fig. 3L; $p=0.0010$ ) and dentate gyrus (Fig. 3P; $p=0.0007$ ), compared to age-matched wild type mice.

3.1.3.5 Synaptophysin is reduced in the polymorphic layer of the dentate gyrus of aged APP/PS1 mice

Representative images illustrate reduced synaptophysin in the hippocampal polymorphic layer of 15-18 month old APP/PS1 mice (Fig. 4D) compared to wild types (Fig. 4A; $p=0.0338$ ). Synaptophysin staining was similar in all other layers of the hippocampus between wild type and APP/PS1 mice and was not significantly different in the granule cell (Fig. 4D), molecular layer (Fig. 4D), strata radiatum (Fig. 4E), pyramidale (Fig. 4E) or oriens (Fig. 4E) of APP/PS1 mice, compared to wild type controls (Fig. 4A and B). Furthermore, synaptophysin optical density did not differ significantly in the inner or outer (Fig. 4F) cortical layers of APP/PS1 mice, compared to age-matched wild types (Fig. 4C). Quantification confirmed that synaptophysin staining was reduced in the polymorphic layer of APP/PS1 mice, but was comparable with wild types in all other layers of the hippocampus and cortex (Fig. 4G). 


\subsubsection{Peripheral insulin sensitivity and glucose tolerance and inflammatory and insulin}

signaling gene expression in brains of aged APP/PS1 mice

Expression of GLP-1R, IKK $\beta$, ERK2, mTOR, NF-кB1, PKC $\theta$ and TLR4 was comparable in brains of aged APP/PS1 and wild type mice and genotype did not have a significant effect on gene expression (Fig. 5A). Additional analysis comparing aged APP/PS1 mice with younger C57B1/6 mice (17-22 weeks old) identified a significant effect of genotype on gene expression (Supplementary Fig. 1A; $<<0.0001$ ) and post-hoc analysis showed that expression of $\operatorname{IKK} \beta(p<0.01)$, ERK2 $(p<0.05)$ and mTOR $(p<0.01)$ was significantly down-regulated and TLR4 $(p<0.05)$ was up-regulated in brains of aged APP/PS1 mice, compared to young C57B1/6 controls. As illustrated in Fig. 5C, in response to an insulin sensitivity test, a significant decrease in blood glucose over time was detected $(p<0.0001)$, however genotype had no significant effect on blood glucose levels. Similarly, glucose tolerance was comparable in both groups and although time significantly affected blood glucose levels $(p<0.0001)$, genotype was not associated with a change in peripheral glucose tolerance (Fig. $5 \mathrm{D})$.

\subsubsection{Cytokine levels in brains of aged APP/PS1 mice}

Brain levels of IFN $\gamma$ (Fig. 6A; $p=0.0046$ ) and IL-4 (Fig. 6F; $p=0.0013$ ) were significantly elevated in brains of 15-18 month-old APP/PS1 mice compared to age-matched wild type mice (Fig. 6A). A trend towards elevated IL-1 $\beta$ was detected in the brains of APP/PS1 mice compared to age-matched wild types, however this failed to reach significance (Fig. 6C; $p=0.0965)$. Additional analysis indicated that IL- $1 \beta$ was significantly elevated in the brains of 15-18 month-old wild type $(p<0.01)$ and APP/PS1 $(p<0.0001)$ mice, compared to young wild types (Supplementary Fig. 1B). A significant increase in IL-4 (Supplementary Fig. 1C; $p<0.001)$ and IFN $\gamma$ (Supplementary Fig. 1D; $p<0.01$ ) was also detected in the brains of aged 
APP/PS1 mice, compared to young wild type mice. In addition, Pearson's correlation analysis identified a significant negative correlation between levels of IFN $\gamma$ and novel object recognition index in APP/PS1 mice (Fig. 7C; $r=-0.8362, p=0.0381$ ), suggesting that higher levels of IFN $\gamma$ in the brain were associated with worse ORT performance in APP/PS1 mice. No significant correlations were identified between IFN $\gamma$ and IRS-1 $\mathrm{pSer}^{616}$ immunopositivity in the cortex or dentate gyrus (Fig. 7D and E).

\section{Discussion}

This study showed that peripheral glucose tolerance and insulin sensitivity were comparable between aged APP/PS1 and wild type mice, conflicting with a number of other studies (24, $25)$. It has been suggested that $5 / 6$ hours fasting is optimal for glucose and insulin tolerance tests, as this was sufficient for normalization of glucose levels and phosphorylation of insulin signaling proteins $(26,27)$. The current study performed glucose tolerance and insulin sensitivity tests following an overnight fasting period, so it is possible that results presented here reflect an exaggerated suppression of basal glucose levels in mice as a result of prolonged fasting. This suggestion is supported by Jimenez-Palomares et al. (28) who also found that glucose tolerance and insulin sensitivity were not significantly different in 8 month-old APP/PS1 mice, compared to wild types following overnight fasting periods. Future studies should avoid overnight fasting prior to glucose and insulin tolerance tests in order to achieve optimal normalization of metabolic parameters and to avert potentially dangerous hypoglycemic effects of insulin. Other reports suggest that insulin insensitivity and glucose intolerance also exists in aged animals (29-31), including C57B1/6 mice (32-34); a possible explanation for the similarity between APP/PS1 mice and controls in the present study. To better understand the impact of central insulin resistance on global insulin utilisation in the APP/PS1 model, future studies should assess the impact of hypothalamic 
insulin administration alone and in combination with insulin sensitising drugs, such as metformin, in hyperinsulinemic euglycemic clamp models.

Recognition memory was impaired in APP/PS1 mice here, consistent with several other studies (35-37). However, since wild type controls also exhibited impaired recognition memory, the deficits may be related to advanced age, rather than the APP/PS1 genotype; a suggestion supported by other studies reporting recognition memory deficits in aged C57Bl/6 mice $(38,39)$. Another study found several indications of cognitive dysfunction in 18-20 month-old C57Bl/6 mice, including impaired novel location memory, but not object recognition memory (40). Spatial learning was impaired in aged APP/PS1 mice, in agreement with other studies $(41,42)$. Spatial memory recall was impaired in APP/PS1 mice and wild type mice, similar to Barreto et al. (43), who showed that spatial learning and memory were impaired in 18 month-old C57B1/6 mice. Other reports have highlighted age-related decline in learning and memory in C57Bl/6 mice $(44,45)$ consistent with the findings of the present study, providing further evidence that there exists age-related deterioration of cognitive function in $\mathrm{C} 57 \mathrm{Bl} / 6$ mice. Learning in the reversal water maze task was impaired in aged APP/PS1 mice, compared to controls, while both APP/PS1 mice and wild types failed to recognize the reversal target quadrant. Some (46), but not others (47) have shown that reversal learning and memory are impaired in APP/PS1 mice. Results presented here, suggest that reversal learning is a cognitive domain that is especially vulnerable to the effects of $\mathrm{AD}$ pathology in aged mice.

Amyloid- $\beta$ (A $\beta)$ deposits were detected throughout the brains of 15-18 month-old APP/PS1 mice, while A $\beta$ was undetectable in wild type controls. APP/PS1 mice develop plaque deposition by 6 months of age, which progressively worsens, leading to abundant and widespread $\mathrm{A} \beta$ plaque pathology by the age of 14 months $(48,49)$. The finding that $\mathrm{A} \beta$ 
deposition was significant in APP/PS1 brains and absent from wild types suggests that the spatial memory deficits in both groups were not directly related to $\mathrm{A} \beta$ burden.

Oxidative stress levels were similar between APP/PS1 and wild type mice in the cortex and dentate gyrus. This was unexpected given previous reports showing elevated oxidative damage in brains of aged APP/PS1 mice (50-52). However, since aging is associated with accumulation of oxidative stress in the brain $(53,54)$, results presented here may reflect age-related accumulation of oxidative DNA damage in both APP/PS1 and wild type mice.

IRS-1 pSer ${ }^{616}$ was increased in brains of APP/PS1 mice, as has also been observed in AD patients $(18,19,55)$ and in experimental models $(55,56)$. The findings of the present study corroborate those of Talbot et al. (18) that demonstrated elevated IRS- 1 pSer ${ }^{616}$ in the hippocampus of APP/PS1 mice. IRS-1 $\mathrm{pSer}^{616}$ has been shown to robustly correlate with cognitive impairment and brain insulin resistance associated with $\mathrm{AD}$ (18) and is likely related to the cognitive impairment in APP/PS1 mice here. It is interesting to note that the increased brain insulin resistance in aged APP/PS1 mice was apparent in the absence of any significant indications of peripheral insulin insensitivity or glucose intolerance.

Astrocytes were increased in the cortex and dentate gyrus of APP/PS1 mice, consistent with previous reports $(50,57)$. Neuroinflammation and glial cell proliferation, recruitment and activation is a commonly associated with AD pathology (13). The fact that A $\beta$ deposition remained substantial in the brains of APP/PS1 mice suggests that clearance of A $\beta$ was minimal, providing support for the proposal that astrocyte function is defective in AD (58). Expression of inflammatory and insulin signaling genes was similar in brains of aged APP/PS1 mice and age-matched wild type controls. It has been shown previously that expression of TLR4 is up-regulated in brains of APP/PS1 and wild type mice in an agerelated manner (59) and the present report provides further evidence that TLR4 expression in 
brain is increased with normal aging, to levels comparable with APP/PS1 mice. Th1 cytokine IFN $\gamma$ was elevated in brains of APP/PS1 mice compared to wild types, in agreement with another study that showed age-related enhancement of IFN $\gamma$ in brains of AD mice from 3 to 19 months of age (60). It has also been shown that IFN $\gamma$ has opposing functions in AD brain, whereby overexpression of IFN $\gamma$ in the hippocampus augments neuroinflammation and worsens $\mathrm{A} \beta$ burden, but abrogates tau pathology and enhances synaptic markers and neurogenesis (61). Further experimentation should determine whether the increased IFN $\gamma$ in brains of APP/PS1 mice here represents a component of pathogenic neuroinflammation or an up-regulation of protective processes. A significant negative correlation was identified here between IFN $\gamma$ levels and novel object recognition memory in APP/PS1 mice, in line with a recent study demonstrating improved hippocampal synaptic plasticity and cognitive performance in mice deficient for IFN $\gamma$ (62), suggesting that increased IFN $\gamma$ in the brain may impair cognitive function in aged APP/PS1 mice. The increase in IFN $\gamma$ is mirrored by a comparable increase in anti-inflammatory IL-4 in brains of APP/PS1 mice, which likely reflects an attempt to suppress the Th1 response. Interestingly IFN $\gamma$ has also been implicated in attenuation of insulin signaling (63) and may be similarly associated with the brain insulin resistance in the present study. Although we failed to detect significant correlations between brain levels of IFN $\gamma$ and IRS-1 pSer $^{616}$, this potential mechanism certainly warrants further exploration.

Previous studies have detected increased IL-1 $\beta$ in the brains of APP/PS1 mice (64, 65). The present report, however, detected a non-significant trend towards an increase in IL$1 \beta$ in the brains of APP/PS1 mice, possibly due to a parallel, age-related elevation of IL- $1 \beta$ in wild-type mice. This suggests that IL-1 $\beta$ is involved with neuroinflammation that accompanies normal aging, while IFN $\gamma$ and IL-4 are not part of the normal process of aging, 
but are components of the neuroinflammatory processes associated with $\mathrm{AD}$, since these were elevated in aged APP/PS1 mice, compared to both young and old wild types.

Expression of mTOR and ERK2 was comparable in brains of aged APP/PS1 mice, compared to wild types. Extracellular signal-regulated kinase 2 (ERK2) signaling facilitates learning and memory $(68,69)$, suggesting that impaired cognitive function in aged mice may be due, in part to reduced expression of ERK2 in the brain. Dineley et al. (70) showed that $\mathrm{A} \beta$ reduces ERK2 activity and that ERK2 expression is down-regulated in brains of 20 month-old AD mice. Similarly, dysregulation of signaling downstream of mTOR has been demonstrated in post-mortem brain tissue from AD patients (71). Signaling through mTOR contributes to synaptic plasticity, learning and memory $(72,73)$. It has also been shown that insulin promotes neurogenesis, dendrite and synapse formation by signaling through IRSmediated activation of mTOR $(74,75)$. Amyloid- $\beta(A \beta)$ perturbs mTOR signaling in neurons (76) and mTOR inhibition impairs hippocampal LTP in an AD mouse model (77). Our results suggest that expression of insulin signaling components is comparable in aged APP/PS1 and wild-type mice. Disruption of insulin signaling in the brain may be involved in the pathophysiology of $\mathrm{AD}$ and may contribute to cognitive impairments associated with aging, a proposition that should be further probed in future studies.

Synaptophysin staining was reduced in the polymorphic layer of the dentate gyrus of APP/PS1 mice. Several previous studies have shown that synapse density is decreased in the brains of APP/PS1 mice (78-80). These studies did not consider the discrete cellular layers of the hippocampus and may have overlooked subtle variation in synapse density between subregions (78-80). However, one report showed that synaptophysin levels in the hippocampus of 7 and 17 month-old APP/PS1 mice were similar to age-matched wild types (81), which more closely aligns with the findings of the present study. It has also been shown in $\operatorname{Tg} 2576$ mice, that synaptophysin levels were no different from controls at 3, 9, 14 and 19 
months of age (82), while $\mathrm{Xu}$ et al. (45) reported age-related decline in hippocampal synaptic spine density in $\mathrm{C} 57 \mathrm{Bl} / 6$ mice. Results of the present report reflect a similar pattern, with synapse density being comparable to wild types in 15-18 month-old APP/PS1 mice. Since synapse density in the polymorphic layer was reduced in aged transgenic mice, it is reasonable to suggest that this subregion was selectively susceptible to synaptotoxicity associated with AD neuropathology.

A limitation of the present study is the absence of young cohorts of wild type and APP/PS1 mice. Based on evidence from the literature, it is likely that peripheral insulin sensitivity, cognitive function and synapse density were influenced by aging. Future studies should include groups of young wild type and transgenic mice in order to more robustly characterize the differences between $\mathrm{AD}$ pathology and changes associated with normal aging, throughout the lifecourse. Another limitation of the present report is that cytokines and mRNA were measured in whole hemi-brains, while analysis of immunohistochemistry was performed on brain sections allowing for quantification within discrete brain regions. This means that comparing the results of our biochemical assays with our immunohistochemical data is difficult. Future studies will analyse mRNA and associated proteins and activation states in discrete brain regions to allow for more accurate demarcation of differences between APP/PS1 mice and wild types with regard to insulin signaling dysregulation and inflammation the brain.

Nevertheless, this study has demonstrated memory deficits and neuroinflammation in aged APP/PS1 and wild type mice. Astrocyte accumulation, IL-1 $\beta$ and IRS- 1 pSer ${ }^{616}$ levels were increased in the brain of APP/PS1 mice in the absence of systemic insulin insensitivity or glucose intolerance. Pharmacological agents targeting impaired insulin signaling and inflammation in the brain may prove efficacious in treating $\mathrm{AD}$, a suggestion requiring further investigation. 


\title{
Acknowledgements
}

Some of the data has been submitted, in abstract form, to the 2017 Southern California Alzheimer's Disease Centers Research Symposium at the University of California, Beckman Center of the National Academies of Sciences \& Engineering, 100 Academy Way, Irvine, CA, USA 92617

\section{Funding}

This work was supported by the Department of Education and Learning, Northern Ireland.

\section{Declaration / Conflict of Interest}

All authors declare that there is no duality of interest associated with their contribution to this manuscript.

\begin{abstract}
Author Contribution Statement
PMcC conceived the study, participated in the analysis and interpretation of data, drafted the manuscript and revised it critically for intellectual content. PD participated in data generation, analysis and interpretation and drafted the manuscript and revised it critically for intellectual content. AE participated in data generation and analysis. All authors approved the final version of the manuscript. PD is the guarantor of this work and, as such, had full access to all the data in the study and takes responsibility for the integrity of the data and the accuracy of the data analysis.
\end{abstract}




\section{References}

1. Global, regional, and national life expectancy, all-cause mortality, and causespecific mortality for 249 causes of death, 1980-2015: a systematic analysis for the Global Burden of Disease Study 2015. Lancet (London, England). 2016;388(10053):1459-544.

2. Querfurth HW, LaFerla FM. Alzheimer's disease. The New England journal of medicine. 2010;362(4):329-44.

3. McKhann GM, Knopman DS, Chertkow H, Hyman BT, Jack CR, Jr., Kawas CH, et al. The diagnosis of dementia due to Alzheimer's disease: recommendations from the National Institute on Aging-Alzheimer's Association workgroups on diagnostic guidelines for Alzheimer's disease. Alzheimer's \& dementia : the journal of the Alzheimer's Association. 2011;7(3):263-9.

4. De-Paula VJ, Radanovic M, Diniz BS, Forlenza OV. Alzheimer's disease. Subcellular biochemistry. 2012;65:329-52.

5. Savva GM, Wharton SB, Ince PG, Forster G, Matthews FE, Brayne C. Age, neuropathology, and dementia. The New England journal of medicine. 2009;360(22):2302-9.

6. Malek-Ahmadi M, Perez SE, Chen K, Mufson EJ. Neuritic and Diffuse Plaque Associations with Memory in Non-Cognitively Impaired Elderly. Journal of Alzheimer's disease : JAD. 2016;53(4):1641-52.

7. Meraz-Rios MA, Toral-Rios D, Franco-Bocanegra D, Villeda-Hernandez J, CamposPena V. Inflammatory process in Alzheimer's Disease. Front Integr Neurosci. 2013;7:59. 8. Rezai-Zadeh K, Gate D, Town T. CNS infiltration of peripheral immune cells: DDay for neurodegenerative disease? Journal of neuroimmune pharmacology : the official journal of the Society on NeuroImmune Pharmacology. 2009;4(4):462-75.

9. Schilling M, Besselmann M, Leonhard C, Mueller M, Ringelstein EB, Kiefer R. Microglial activation precedes and predominates over macrophage infiltration in transient focal cerebral ischemia: a study in green fluorescent protein transgenic bone marrow chimeric mice. Experimental neurology. 2003;183(1):25-33.

10. Fu Y, Hsiao JT, Paxinos G, Halliday GM, Kim WS. ABCA7 Mediates Phagocytic Clearance of Amyloid-beta in the Brain. Journal of Alzheimer's disease : JAD. 2016;54(2):569-84.

11. El-Shimy IA, Heikal OA, Hamdi N. Minocycline attenuates Abeta oligomersinduced pro-inflammatory phenotype in primary microglia while enhancing Abeta fibrils phagocytosis. Neuroscience letters. 2015;609:36-41.

12. Leszek J, Barreto GE, Gasiorowski K, Koutsouraki E, Avila-Rodrigues M, Aliev G. Inflammatory Mechanisms and Oxidative Stress as Key Factors Responsible for Progression of Neurodegeneration: Role of Brain Innate Immune System. CNS \& neurological disorders drug targets. 2016;15(3):329-36.

13. Steardo L, Jr., Bronzuoli MR, Iacomino A, Esposito G, Steardo L, Scuderi C. Does neuroinflammation turn on the flame in Alzheimer's disease? Focus on astrocytes. Frontiers in neuroscience. 2015;9:259.

14. Gabuzda D, Yankner BA. Physiology: Inflammation links ageing to the brain. Nature. 2013;497(7448):197-8.

15. Maher FO, Martin DS, Lynch MA. Increased IL-1beta in cortex of aged rats is accompanied by downregulation of ERK and PI-3 kinase. Neurobiology of aging. 2004;25(6):795-806. 
16. Godbout JP, Chen J, Abraham J, Richwine AF, Berg BM, Kelley KW, et al. Exaggerated neuroinflammation and sickness behavior in aged mice following activation of the peripheral innate immune system. FASEB journal : official publication of the Federation of American Societies for Experimental Biology. 2005;19(10):132931.

17. Hong S, Beja-Glasser VF, Nfonoyim BM, Frouin A, Li S, Ramakrishnan S, et al. Complement and microglia mediate early synapse loss in Alzheimer mouse models. Science (New York, NY). 2016;352(6286):712-6.

18. Talbot K, Wang HY, Kazi H, Han LY, Bakshi KP, Stucky A, et al. Demonstrated brain insulin resistance in Alzheimer's disease patients is associated with IGF-1 resistance, IRS-1 dysregulation, and cognitive decline. The Journal of clinical investigation. 2012;122(4):1316-38.

19. Bomfim TR, Forny-Germano L, Sathler LB, Brito-Moreira J, Houzel JC, Decker H, et al. An anti-diabetes agent protects the mouse brain from defective insulin signaling caused by Alzheimer's disease- associated Abeta oligomers. The Journal of clinical investigation. 2012;122(4):1339-53.

20. Moloney AM, Griffin RJ, Timmons S, O'Connor R, Ravid R, O'Neill C. Defects in IGF-1 receptor, insulin receptor and IRS-1/2 in Alzheimer's disease indicate possible resistance to IGF-1 and insulin signalling. Neurobiology of aging. 2010;31(2):224-43.

21. Liu Y, Liu F, Grundke-Iqbal I, Iqbal K, Gong CX. Deficient brain insulin signalling pathway in Alzheimer's disease and diabetes. The Journal of pathology. 2011;225(1):54-62.

22. McClean PL, Parthsarathy V, Faivre E, Holscher C. The diabetes drug liraglutide prevents degenerative processes in a mouse model of Alzheimer's disease. The Journal of neuroscience : the official journal of the Society for Neuroscience. 2011;31(17):658794.

23. Livak KJ, Schmittgen TD. Analysis of relative gene expression data using realtime quantitative PCR and the 2(-Delta Delta C(T)) Method. Methods (San Diego, Calif). 2001;25(4):402-8.

24. Clarke JR, Lyra ESNM, Figueiredo CP, Frozza RL, Ledo JH, Beckman D, et al. Alzheimer-associated Abeta oligomers impact the central nervous system to induce peripheral metabolic deregulation. EMBO molecular medicine. 2015;7(2):190-210.

25. Pedros I, Petrov D, Allgaier M, Sureda F, Barroso E, Beas-Zarate C, et al. Early alterations in energy metabolism in the hippocampus of APPswe/PS1dE9 mouse model of Alzheimer's disease. Biochimica et biophysica acta. 2014;1842(9):1556-66.

26. Andrikopoulos S, Blair AR, Deluca N, Fam BC, Proietto J. Evaluating the glucose tolerance test in mice. American journal of physiology Endocrinology and metabolism. 2008;295(6):E1323-32.

27. Agouni A, Owen C, Czopek A, Mody N, Delibegovic M. In vivo differential effects of fasting, re-feeding, insulin and insulin stimulation time course on insulin signaling pathway components in peripheral tissues. Biochemical and biophysical research communications. 2010;401(1):104-11.

28. Jimenez-Palomares M, Ramos-Rodriguez JJ, Lopez-Acosta JF, Pacheco-Herrero M, Lechuga-Sancho AM, Perdomo G, et al. Increased Abeta production prompts the onset of glucose intolerance and insulin resistance. American journal of physiology Endocrinology and metabolism. 2012;302(11):E1373-80.

29. Catalano KJ, Bergman RN, Ader M. Increased susceptibility to insulin resistance associated with abdominal obesity in aging rats. Obesity research. 2005;13(1):11-20. 
30. Yamamoto M, Otsuki M. Effect of inhibition of alpha-glucosidase on age-related glucose intolerance and pancreatic atrophy in rats. Metabolism: clinical and experimental. 2006;55(4):533-40.

31. Romanatto T, Fiamoncini J, Wang B, Curi R, Kang JX. Elevated tissue omega-3 fatty acid status prevents age-related glucose intolerance in fat- 1 transgenic mice. Biochimica et biophysica acta. 2014;1842(2):186-91.

32. Houtkooper RH, Argmann C, Houten SM, Canto C, Jeninga EH, Andreux PA, et al. The metabolic footprint of aging in mice. Scientific reports. 2011;1:134.

33. Lipina C, Vaanholt LM, Davidova A, Mitchell SE, Storey-Gordon E, Hambly C, et al. CB1 receptor blockade counters age-induced insulin resistance and metabolic dysfunction. Aging cell. 2016;15(2):325-35.

34. Park D, Lee EK, Jang EJ, Jeong HO, Kim BC, Ha YM, et al. Identification of the dichotomous role of age-related LCK in calorie restriction revealed by integrative analysis of cDNA microarray and interactome. Age (Dordrecht, Netherlands). 2013;35(4):1045-60.

35. Gu XH, Xu LJ, Liu ZQ, Wei B, Yang YJ, Xu GG, et al. The flavonoid baicalein rescues synaptic plasticity and memory deficits in a mouse model of Alzheimer's disease. Behavioural brain research. 2016;311:309-21.

36. Yang YJ, Zhao Y, Yu B, Xu GG, Wang W, Zhan JQ, et al. GluN2B-containing NMDA receptors contribute to the beneficial effects of hydrogen sulfide on cognitive and synaptic plasticity deficits in APP/PS1 transgenic mice. Neuroscience. 2016;335:170-83. 37. Zhou D, Liu H, Li C, Wang F, Shi Y, Liu L, et al. Atorvastatin ameliorates cognitive impairment, Abeta1-42 production and Tau hyperphosphorylation in APP/PS1 transgenic mice. Metabolic brain disease. 2016;31(3):693-703.

38. Qiu J, Dunbar DR, Noble J, Cairns C, Carter R, Kelly V, et al. Decreased Npas4 and Arc mRNA Levels in the Hippocampus of Aged Memory-Impaired Wild-Type But Not Memory Preserved 11beta-HSD1 Deficient Mice. Journal of neuroendocrinology. 2016;28(1).

39. Mechan AO, Wyss A, Rieger H, Mohajeri MH. A comparison of learning and memory characteristics of young and middle-aged wild-type mice in the IntelliCage. Journal of neuroscience methods. 2009;180(1):43-51.

40. Benice TS, Rizk A, Kohama S, Pfankuch T, Raber J. Sex-differences in age-related cognitive decline in C57BL/6J mice associated with increased brain microtubuleassociated protein 2 and synaptophysin immunoreactivity. Neuroscience. 2006;137(2):413-23.

41. Fol R, Braudeau J, Ludewig S, Abel T, Weyer SW, Roederer JP, et al. Viral gene transfer of APPsalpha rescues synaptic failure in an Alzheimer's disease mouse model. Acta neuropathologica. 2016;131(2):247-66.

42. Xiao Q, Shi R, Yang W, Zou Y, Du Y, Zhang M, et al. Time-Dependent Increase of Chitinase1 in APP/PS1 Double Transgenic Mice. Neurochemical research. 2016;41(7):1604-11.

43. Barreto G, Huang TT, Giffard RG. Age-related defects in sensorimotor activity, spatial learning, and memory in C57BL/6 mice. Journal of neurosurgical anesthesiology. 2010;22(3):214-9.

44. Shoji H, Takao K, Hattori S, Miyakawa T. Age-related changes in behavior in C57BL/6J mice from young adulthood to middle age. Molecular brain. 2016;9:11.

45. Xu B, Sun A, He Y, Qian F, Liu L, Chen Y, et al. Running-induced memory enhancement correlates with the preservation of thin spines in the hippocampal area CA1 of old C57BL/6 mice. Neurobiology of aging. 2017;52:106-16. 
46. Cheng D, Low JK, Logge W, Garner B, Karl T. Novel behavioural characteristics of female APPSwe/PS1DeltaE9 double transgenic mice. Behavioural brain research. 2014;260:111-8.

47. O'Leary TP, Brown RE. Visuo-spatial learning and memory deficits on the Barnes maze in the 16-month-old APPswe/PS1dE9 mouse model of Alzheimer's disease. Behavioural brain research. 2009;201(1):120-7.

48. Gallagher JJ, Minogue AM, Lynch MA. Impaired performance of female APP/PS1 mice in the Morris water maze is coupled with increased Abeta accumulation and microglial activation. Neuro-degenerative diseases. 2013;11(1):33-41.

49. McManus RM, Higgins SC, Mills KH, Lynch MA. Respiratory infection promotes T cell infiltration and amyloid-beta deposition in APP/PS1 mice. Neurobiology of aging. 2014;35(1):109-21.

50. Duffy AM, Holscher C. The incretin analogue D-Ala2GIP reduces plaque load, astrogliosis and oxidative stress in an APP/PS1 mouse model of Alzheimer's disease. Neuroscience. 2013;228:294-300.

51. Jin JL, Liou AK, Shi Y, Yin KL, Chen L, Li LL, et al. CART treatment improves memory and synaptic structure in APP/PS1 mice. Scientific reports. 2015;5:10224.

52. Yun HM, Jin P, Park KR, Hwang J, Jeong HS, Kim EC, et al. Thiacremonone Potentiates Anti-Oxidant Effects to Improve Memory Dysfunction in an APP/PS1 Transgenic Mice Model. Molecular neurobiology. 2016;53(4):2409-20.

53. Chakrabarti S, Munshi S, Banerjee K, Thakurta IG, Sinha M, Bagh MB. Mitochondrial Dysfunction during Brain Aging: Role of Oxidative Stress and Modulation by Antioxidant Supplementation. Aging and disease. 2011;2(3):242-56.

54. Manczak M, Jung Y, Park BS, Partovi D, Reddy PH. Time-course of mitochondrial gene expressions in mice brains: implications for mitochondrial dysfunction, oxidative damage, and cytochrome $c$ in aging. Journal of neurochemistry. 2005;92(3):494-504.

55. Yarchoan M, Toledo JB, Lee EB, Arvanitakis Z, Kazi H, Han LY, et al. Abnormal serine phosphorylation of insulin receptor substrate 1 is associated with tau pathology in Alzheimer's disease and tauopathies. Acta neuropathologica. 2014;128(5):679-89.

56. Zhang B, Tang XC, Zhang HY. Alternations of central insulin-like growth factor-1 sensitivity in APP/PS1 transgenic mice and neuronal models. Journal of neuroscience research. 2013;91(5):717-25.

57. Galea E, Morrison W, Hudry E, Arbel-Ornath M, Bacskai BJ, Gomez-Isla T, et al. Topological analyses in APP/PS1 mice reveal that astrocytes do not migrate to amyloidbeta plaques. Proceedings of the National Academy of Sciences of the United States of America. 2015;112(51):15556-61.

58. Mulder SD, Veerhuis R, Blankenstein MA, Nielsen HM. The effect of amyloid associated proteins on the expression of genes involved in amyloid-beta clearance by adult human astrocytes. Experimental neurology. 2012;233(1):373-9.

59. Lopez-Gonzalez I, Schluter A, Aso E, Garcia-Esparcia P, Ansoleaga B, F LL, et al. Neuroinflammatory signals in Alzheimer disease and APP/PS1 transgenic mice: correlations with plaques, tangles, and oligomeric species. Journal of neuropathology and experimental neurology. 2015;74(4):319-44.

60. Abbas N, Bednar I, Mix E, Marie S, Paterson D, Ljungberg A, et al. Up-regulation of the inflammatory cytokines IFN-gamma and IL-12 and down-regulation of IL-4 in cerebral cortex regions of APP(SWE) transgenic mice. Journal of neuroimmunology. 2002;126(1-2):50-7. 
61. Mastrangelo MA, Sudol KL, Narrow WC, Bowers WJ. Interferon-\{gamma\} differentially affects Alzheimer's disease pathologies and induces neurogenesis in triple transgenic-AD mice. The American journal of pathology. 2009;175(5):2076-88.

62. Monteiro S, Ferreira FM, Pinto V, Roque S, Morais M, de Sa-Calcada D, et al. Absence of IFNgamma promotes hippocampal plasticity and enhances cognitive performance. Translational psychiatry. 2016;6:e707.

63. McGillicuddy FC, Chiquoine EH, Hinkle CC, Kim RJ, Shah R, Roche HM, et al. Interferon gamma attenuates insulin signaling, lipid storage, and differentiation in human adipocytes via activation of the JAK/STAT pathway. The Journal of biological chemistry. 2009;284(46):31936-44.

64. Xuan AG, Pan XB, Wei P, Ji WD, Zhang WJ, Liu JH, et al. Valproic acid alleviates memory deficits and attenuates amyloid-beta deposition in transgenic mouse model of Alzheimer's disease. Molecular neurobiology. 2015;51(1):300-12.

65. Guo HB, Cheng YF, Wu JG, Wang CM, Wang HT, Zhang C, et al. Donepezil improves learning and memory deficits in APP/PS1 mice by inhibition of microglial activation. Neuroscience. 2015;290:530-42.

66. Salminen A, Ojala J, Suuronen T, Kaarniranta K, Kauppinen A. Amyloid-beta oligomers set fire to inflammasomes and induce Alzheimer's pathology. Journal of cellular and molecular medicine. 2008;12(6a):2255-62.

67. Heneka MT, Kummer MP, Stutz A, Delekate A, Schwartz S, Vieira-Saecker A, et al. NLRP3 is activated in Alzheimer's disease and contributes to pathology in APP/PS1 mice. Nature. 2013;493(7434):674-8.

68. Thomas GM, Huganir RL. MAPK cascade signalling and synaptic plasticity. Nature reviews Neuroscience. 2004;5(3):173-83.

69. Satoh Y, Endo S, Ikeda T, Yamada K, Ito M, Kuroki M, et al. Extracellular signalregulated kinase 2 (ERK2) knockdown mice show deficits in long-term memory; ERK2 has a specific function in learning and memory. The Journal of neuroscience : the official journal of the Society for Neuroscience. 2007;27(40):10765-76.

70. Dineley KT, Westerman M, Bui D, Bell K, Ashe KH, Sweatt JD. Beta-amyloid activates the mitogen-activated protein kinase cascade via hippocampal alpha7 nicotinic acetylcholine receptors: In vitro and in vivo mechanisms related to Alzheimer's disease. The Journal of neuroscience : the official journal of the Society for Neuroscience. 2001;21(12):4125-33.

71. Yates SC, Zafar A, Hubbard P, Nagy S, Durant S, Bicknell R, et al. Dysfunction of the mTOR pathway is a risk factor for Alzheimer's disease. Acta neuropathologica communications. 2013;1:3.

72. Sosanya NM, Cacheaux LP, Workman ER, Niere F, Perrone-Bizzozero NI, RaabGraham KF. Mammalian Target of Rapamycin (mTOR) Tagging Promotes Dendritic Branch Variability through the Capture of Ca2+/Calmodulin-dependent Protein Kinase II alpha (CaMKIIalpha) mRNAs by the RNA-binding Protein HuD. The Journal of biological chemistry. 2015;290(26):16357-71.

73. Garza-Lombo C, Gonsebatt ME. Mammalian Target of Rapamycin: Its Role in Early Neural Development and in Adult and Aged Brain Function. Frontiers in cellular neuroscience. 2016;10:157.

74. Lee CC, Huang CC, Hsu KS. Insulin promotes dendritic spine and synapse formation by the PI3K/Akt/mTOR and Rac1 signaling pathways. Neuropharmacology. 2011;61(4):867-79. 
75. Zhang J, Ji F, Liu Y, Lei X, Li H, Ji G, et al. Ezh2 regulates adult hippocampal neurogenesis and memory. The Journal of neuroscience : the official journal of the Society for Neuroscience. 2014;34(15):5184-99.

76. Chen TJ, Wang DC, Chen SS. Amyloid-beta interrupts the PI3K-Akt-mTOR signaling pathway that could be involved in brain-derived neurotrophic factor-induced Arc expression in rat cortical neurons. Journal of neuroscience research. 2009;87(10):2297-307.

77. Ma T, Hoeffer CA, Capetillo-Zarate E, Yu F, Wong H, Lin MT, et al. Dysregulation of the mTOR pathway mediates impairment of synaptic plasticity in a mouse model of Alzheimer's disease. PloS one. 2010;5(9).

78. Liu SJ, Yang C, Zhang Y, Su RY, Chen JL, Jiao MM, et al. Neuroprotective effect of beta-asarone against Alzheimer's disease: regulation of synaptic plasticity by increased expression of SYP and GluR1. Drug design, development and therapy. 2016;10:1461-9.

79. Ostapchenko VG, Chen M, Guzman MS, Xie YF, Lavine N, Fan J, et al. The Transient Receptor Potential Melastatin 2 (TRPM2) Channel Contributes to beta-Amyloid Oligomer-Related Neurotoxicity and Memory Impairment. The Journal of neuroscience : the official journal of the Society for Neuroscience. 2015;35(45):15157-69.

80. Zhang Y, Huang LJ, Shi S, Xu SF, Wang XL, Peng Y. L-3-n-butylphthalide Rescues Hippocampal Synaptic Failure and Attenuates Neuropathology in Aged APP/PS1 Mouse Model of Alzheimer's Disease. CNS neuroscience \& therapeutics. 2016.

81. Minkeviciene $\mathrm{R}$, Ihalainen J, Malm T, Matilainen 0 , Keksa-Goldsteine V, Goldsteins G, et al. Age-related decrease in stimulated glutamate release and vesicular glutamate transporters in APP/PS1 transgenic and wild-type mice. Journal of neurochemistry. 2008;105(3):584-94.

82. King DL, Arendash GW. Maintained synaptophysin immunoreactivity in Tg2576 transgenic mice during aging: correlations with cognitive impairment. Brain research. 2002;926(1-2):58-68.

\section{Figure Legends}

Figure 1. Learning and memory in aged APP/PS1 and wild type mice. The acquisition training phase of the Morris water maze (MWM) involved four training sessions per day over four consecutive days, followed by a probe trial on the fifth day, 24 hours following the final training session. Escape latency during the training phase is shown (A), as is the proportion of time spent in each quadrant during the probe trial by $15-18$ month-old wild type (solid line with circles; D) and APP/PS1 (dotted line with squares; G) mice. Reversal water maze acquisition training began 24 hours following the MWM probe trial and consisted of four consecutive days with four training sessions per day, followed by a reversal probe trial on the fifth day. Illustrated are training phase escape latency $(\mathbf{B})$ and time spent in each quadrant during the reversal probe trial by wild type $(\mathbf{E})$ and APP/PS1 $(\mathbf{H})$ mice. For 


\section{Figure 2. A $\beta$ deposition and IRS-1 pSer $^{616}$ in the cerebral cortex and dentate gyrus of} aged APP/PS1 and wild type mice. Representative images (10x magnification) are shown that depict $A \beta$ staining in the cerebral cortex $(\mathbf{A})$ and dentate gyrus $(\mathbf{B})$ of 15-18 month old wild type mice and the cerebral cortex (E) and dentate gyrus (F) of age-matched APP/PS1 mice. Also shown is an exemplary magnified image (20x magnification) of $A \beta$ staining in brains of wild type $(\mathbf{C})$ and APP/PS1 (G) mice. Quantification of A $\beta$ immunopositivity in the cortex (D) and dentate gyrus (H) of 15-18 month old APP/PS1 and wild type mice is also shown. Representative images (20x magnification) are also shown that depict IRS-1 pSer ${ }^{616}$ staining in the cerebral cortex (I) and dentate gyrus (J) of 15-18 month old wild type mice and the cerebral cortex $(\mathrm{M})$ and dentate gyrus $(\mathbf{N})$ of age-matched APP/PS1 mice. Also shown are exemplary magnified images (40x magnification) from wild type (K) and APP/PS1 (O) mice. Quantification of IRS-1 pSer $^{616}$ immunopositivity in cortex (L) and dentate gyrus (P) of 15-18 month old APP/PS1 and wild type mice is also illustrated. ${ }^{*} p<0.05, * * * * p<0.0001$, Student's $t$ test. Data represent mean \pm SEM for 6 per group.

Figure 3. Oxidative stress and astrocytes in the cerebral cortex and dentate gyrus of aged APP/PS1 and wild type mice. Representative images (20x magnification) are shown 


\section{Figure 4. Synapse density is decreased in the polymorphic layer of the dentate gyrus in} APP/PS1 mice. Illustrated are representative images depicting synaptophysin staining of brain sections from 15-18 month-old wild type $(\mathbf{A}, \mathbf{B}, \mathbf{C})$ and APP/PS1 (D, E, F) mice. A and $\mathbf{D}$ show the polymorphic layer (PL), granule cell layer (GCL) and molecular layer (ML) of the dentate gyrus. $\mathbf{C}$ and $\mathbf{D}$ show the stratum radiatum (SR), stratum pyramidale (SP) and stratum oriens (SO) of the hippocampus, while $\mathbf{B}$ and $\mathbf{E}$ show the inner (IC) and outer (OC) cerebral cortex. Also illustrated is quantification of synaptophysin optical density values for the polymorphic layer, granule cell layer and molecular layer of the dentate gyrus and the stratum radiatum, stratum pyramidale and stratum oriens of the hippocampus, inner and outer cortex of 15-18 month-old APP/PS1 and wild type mice $(\mathbf{G}) .{ }^{*} p<0.05$; Student's $t$ tests. Data represent mean \pm SEM for 6 per group. 
Figure 5. Peripheral insulin sensitivity, glucose tolerance and expression of

Figure 6. Cytokine levels in the brains of aged APP/PS1 and wild type mice. MSD multiplex analysis of 8 cytokines was performed on supernatant extracted from brain tissue. Protein levels of IFN $\gamma(\mathbf{A})$, IL-10 (B), IL-1 $\beta$ (C), IL-12p70 (D), IL-2 (E), IL-4 (F), IL-5 (E), IL-6 (G) and KC/GRO (CXCL1) (H) were measured and compared between 15-18 monthold APP/PS1 mice (black bars) and age-matched wild types (white bars). ${ }^{* *} p<0.01$; Student's $t$ tests. Data represent mean \pm SEM for 6 per group..

Figure 7. Correlations between IFN $\gamma$, IRS-1 pSer $^{616}$ and novel object recognition memory in aged APP/PS1 and wild type mice. Pearson's correlation analysis was performed between IRS-1 pSer $^{616}$ immunopositivity and novel object recognition index (A, B), between IFN $\gamma$ and novel object recognition index (C) and between IFN $\gamma$ and IRS-1 $\operatorname{pSer}^{616}$ immunopositivity (D, E) in wild type (open circles and dotted best fit line) and APP/PS1 (black squares and solid best fit line) mice. Lines of best fit, $r$ and $p$ values were 
also added to the graphs. Each data point represents an $X Y$ pair for a total of $6 X Y$ pairs per genotype on each graph. Significance of correlation was determined using two-tailed $t$ tests.

\section{Supplementary Figure 1. Cytokines and gene expression in brains of young wild type} mice. Quantification of expression of inflammatory and insulin signaling genes in the brains of young wild type mice (17-22 weeks old) is shown (black bars), compared to aged wild types (white bars) and APP/PS1 mice (dark grey bars) (A). Also illustrated are brain levels of IFN $\gamma(\mathbf{B})$, IL-1 $\beta$ (C) and IL-4 (D) in young wild type mice, compared with aged wild types and APP/PS1 mice. ${ }^{*} p<0.05,{ }^{* *} p<0.01,{ }^{* * *} p<0.001, * * * * p<0.0001$; ordinary one-way ANOVA with Holm-Šídák's post-hoc test (A) and Student's $t$ test (B-D). Data represent mean \pm SEM for $5(A)$ or 6 (B-D) per group. 
Denver et al. Inflammation, insulin signaling and cognitive function in aged APP/PS1 mice

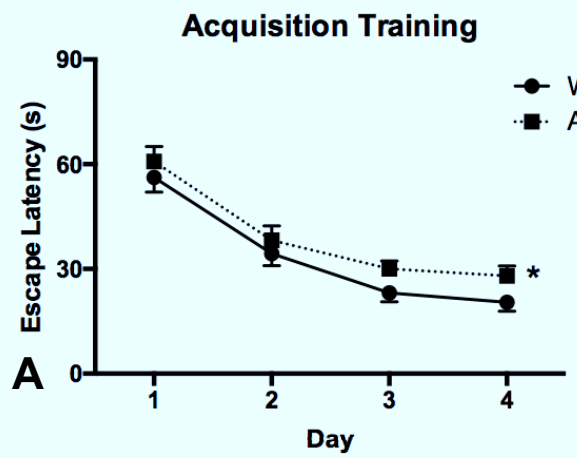

Wild type Probe Trial
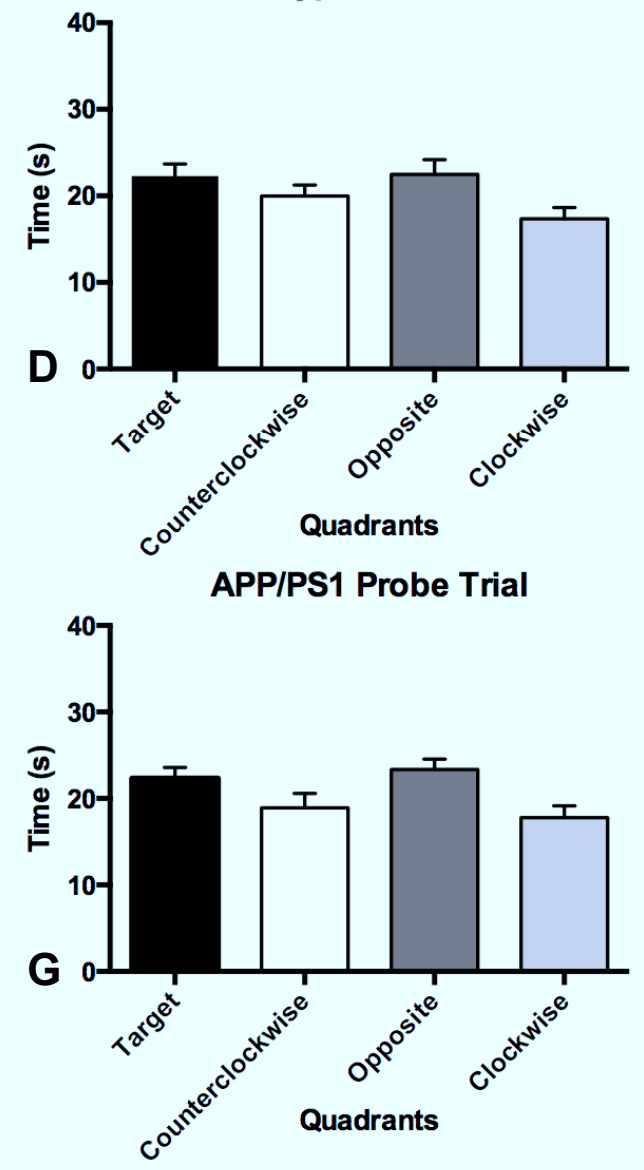

Reversal Acquisition Training

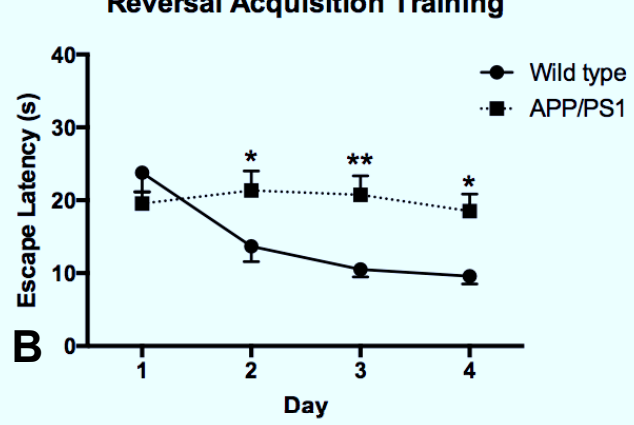

Wild type Reversal Probe Trial

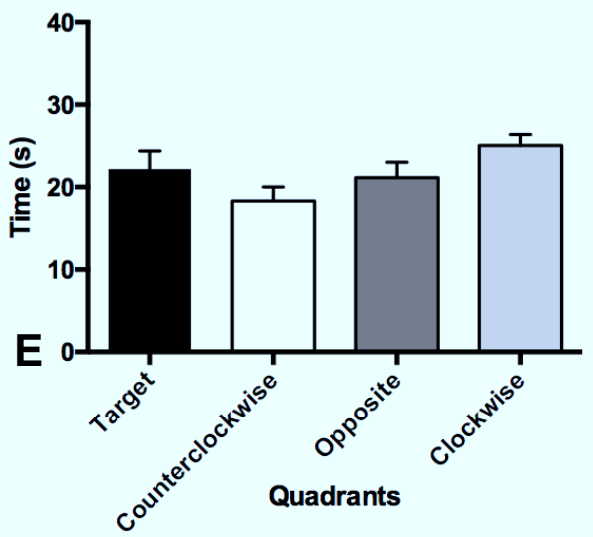

APP/PS1 Reversal Probe Trial

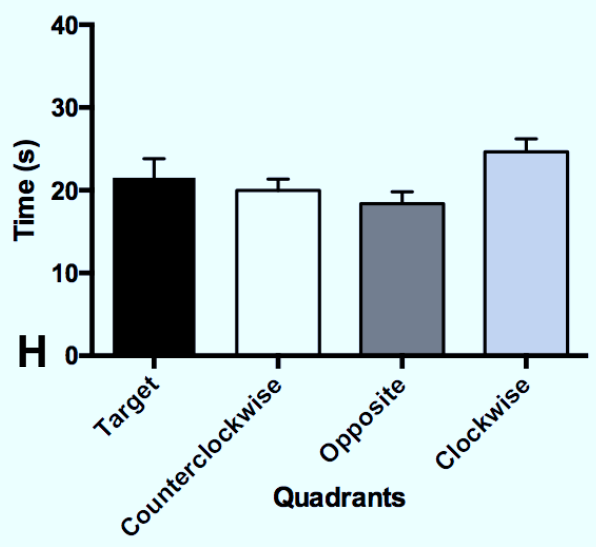

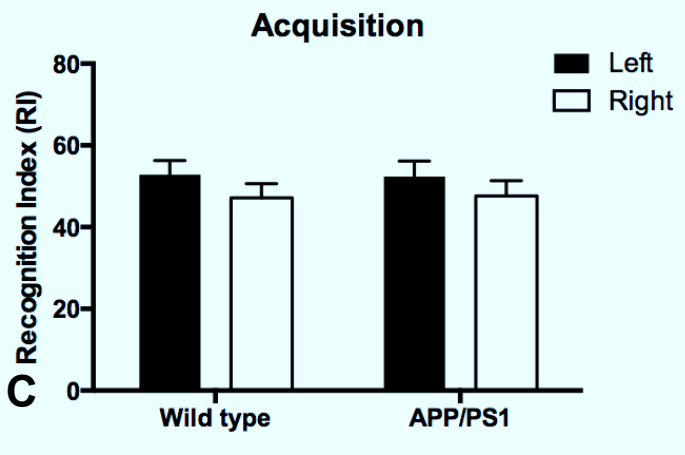

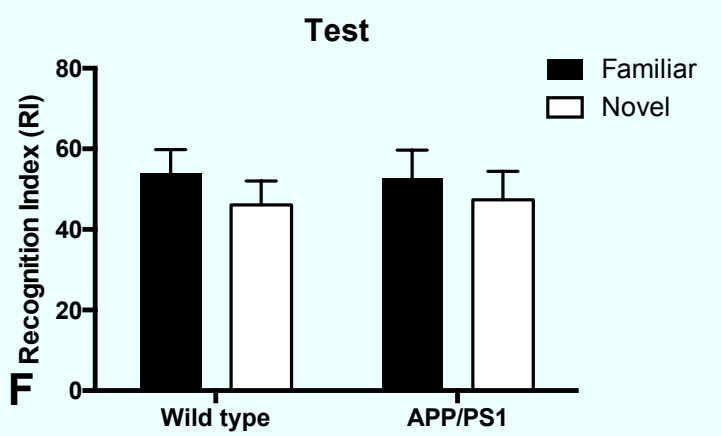


Click here to download high resolution image

Denver et al. Inflammation, insulin signaling and cognitive function in aged APP/PS1 mice
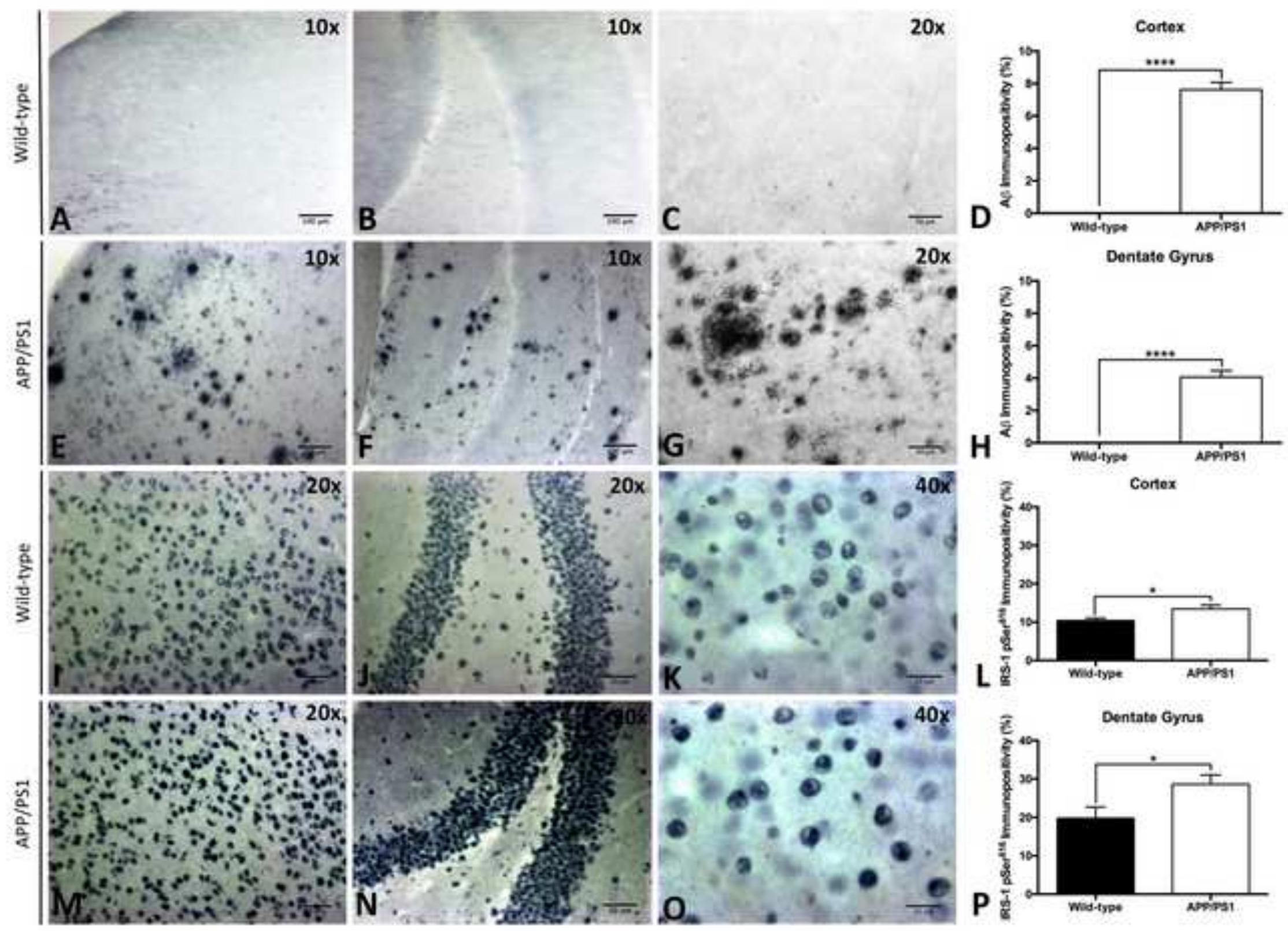
Click here to download high resolution image

Denver et al. Inflammation, insulin signaling and cognitive function in aged APP/PS1 mice
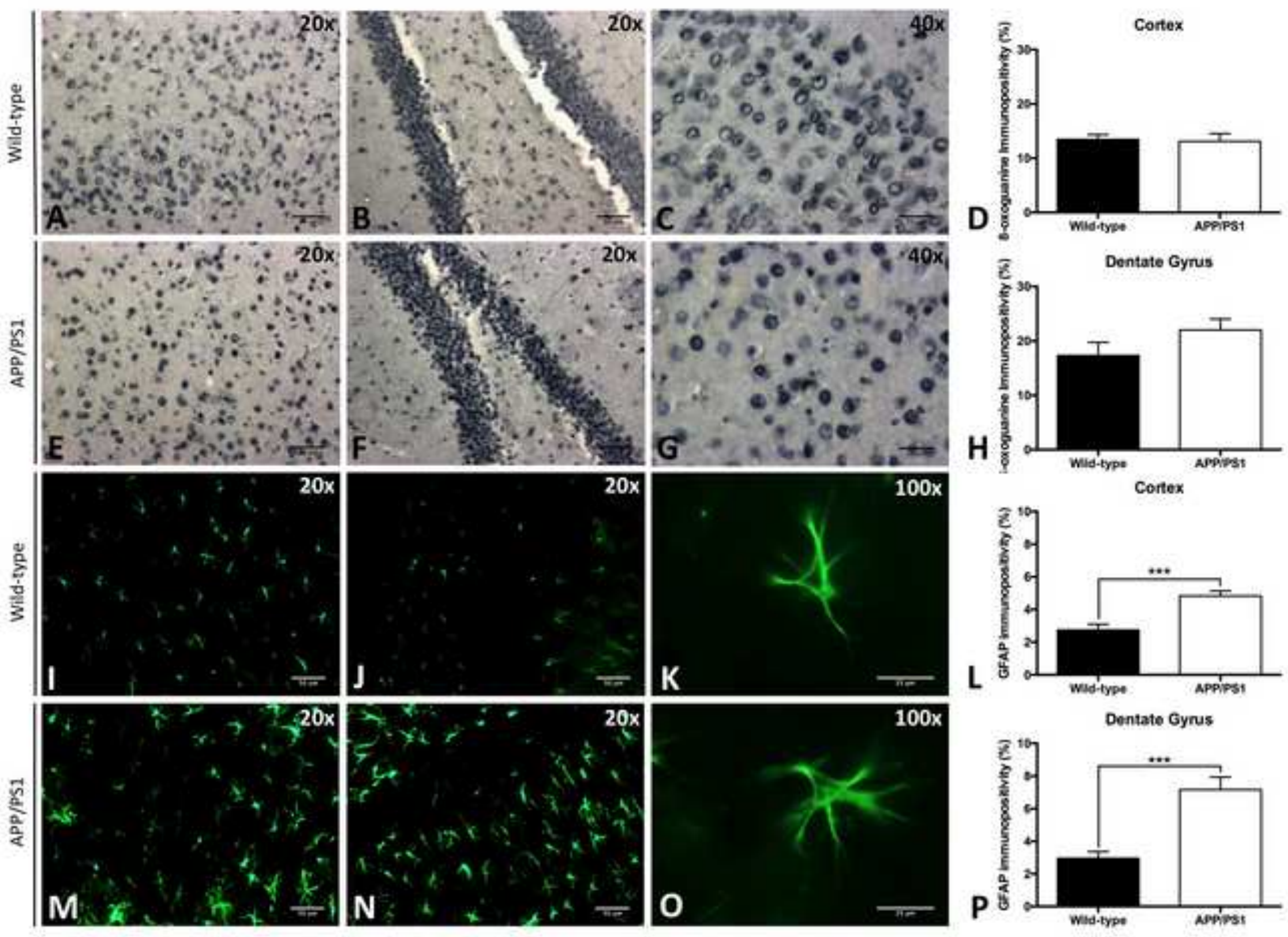
Click here to download high resolution image

Denver et al. Inflammation, insulin signaling and cognitive function in aged APP/PS1 mice
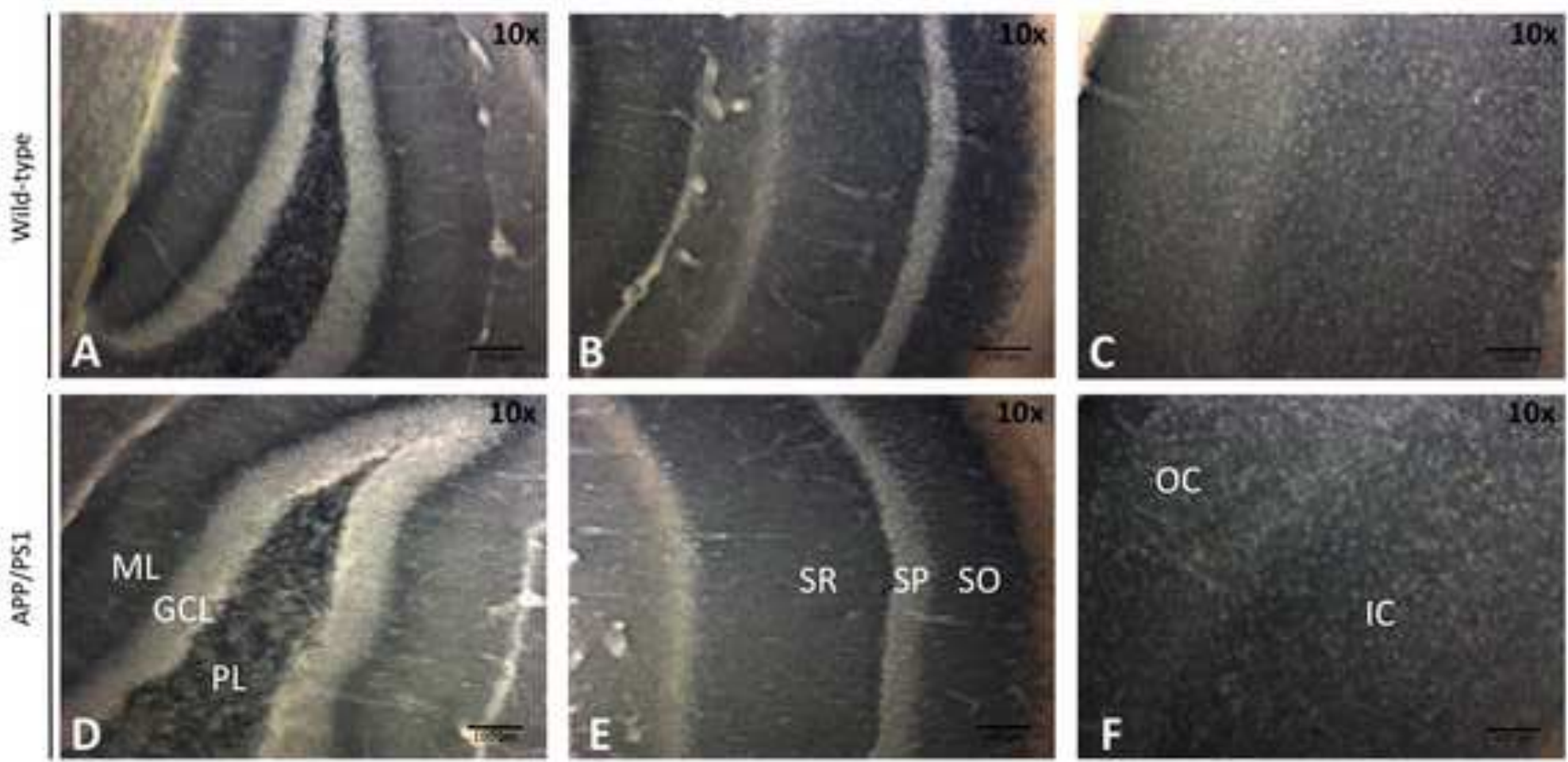

Synaptophysin

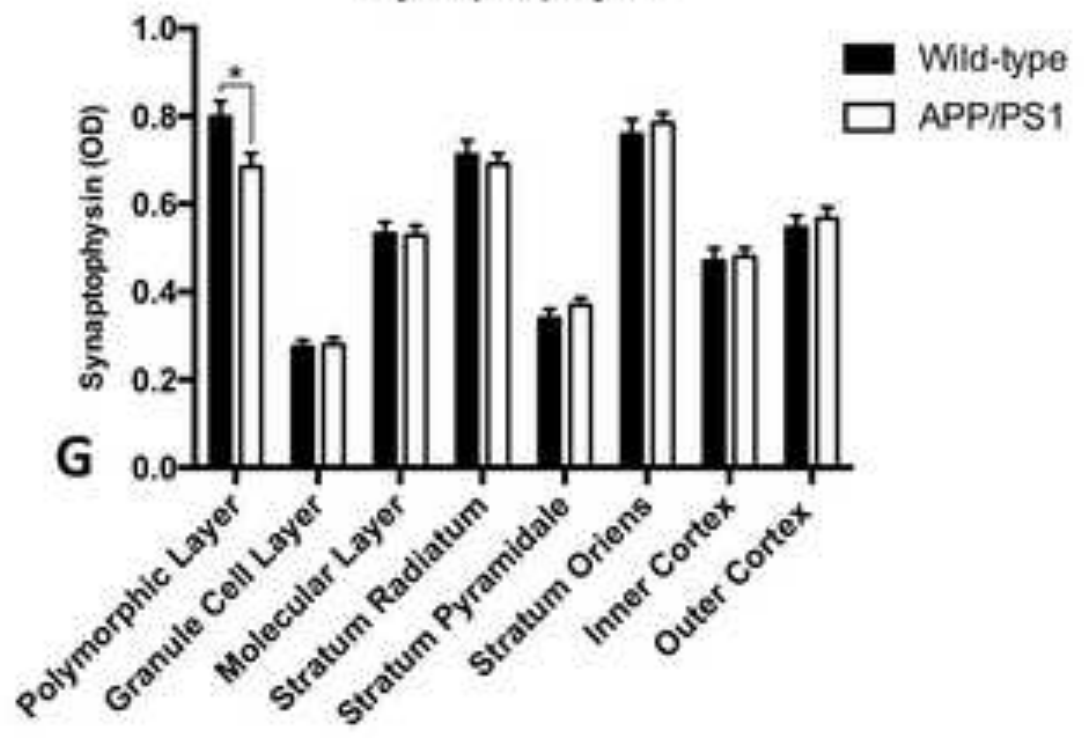


Figure 5 (revised)

Denver et al. Inflammation, insulin signaling and cognitive function in aged APP/PS1 mice
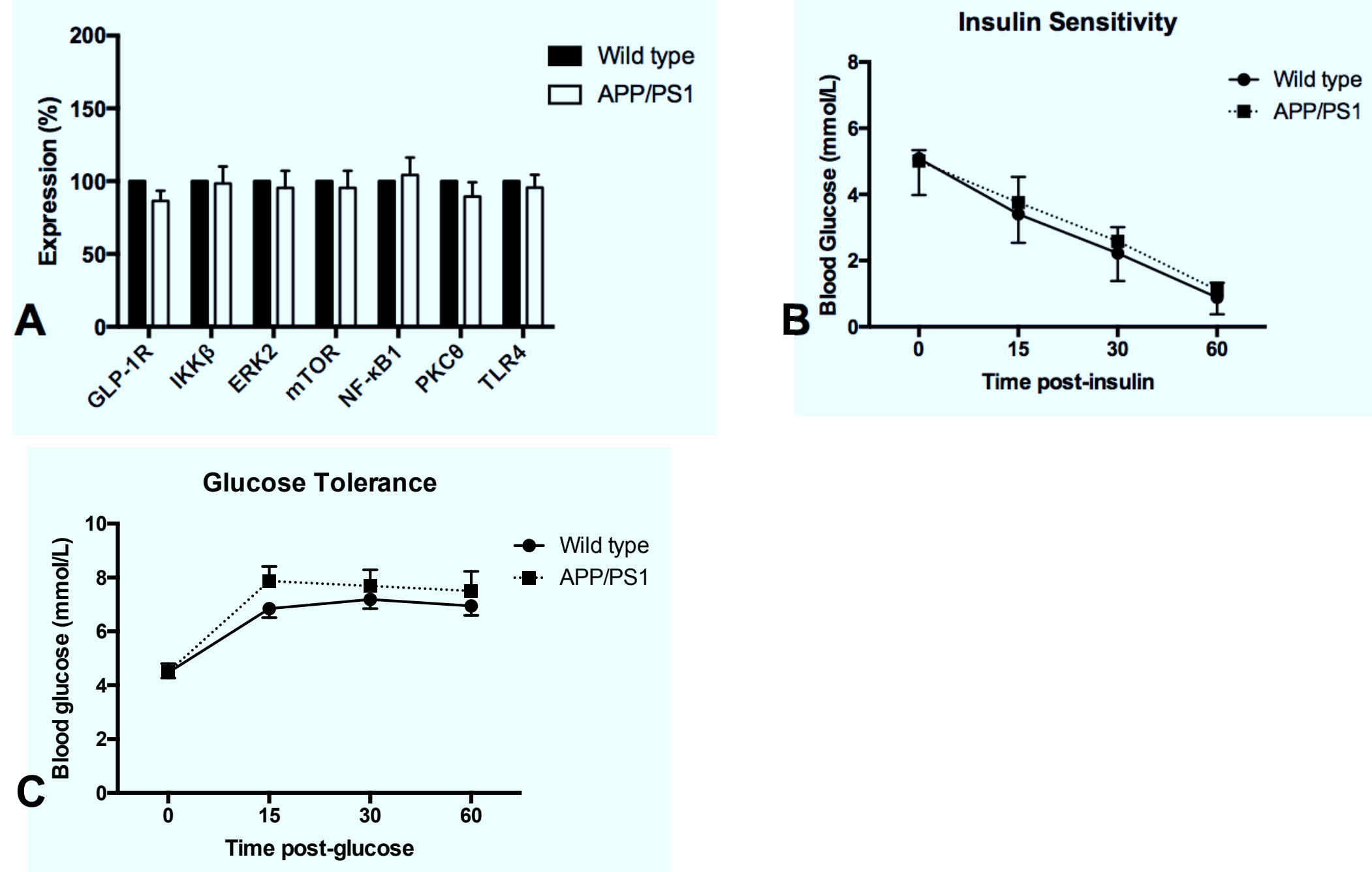
Figure 6 (revised)

Denver et al. Inflammation, insulin signaling and cognitive function in aged APP/PS1 mice

IFN-Y

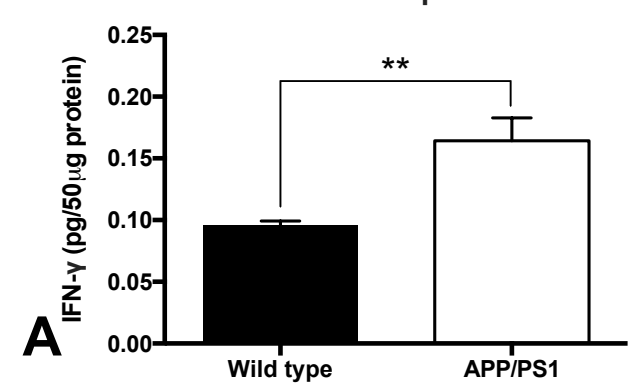

IL-12p70

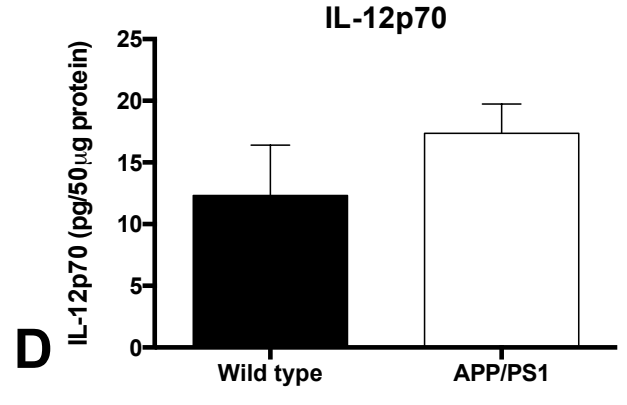

IL-6

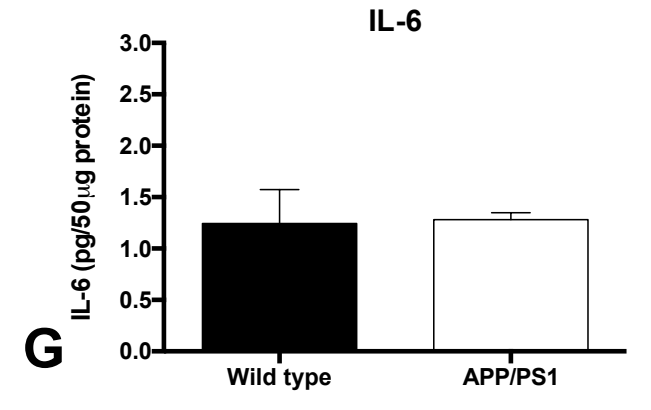

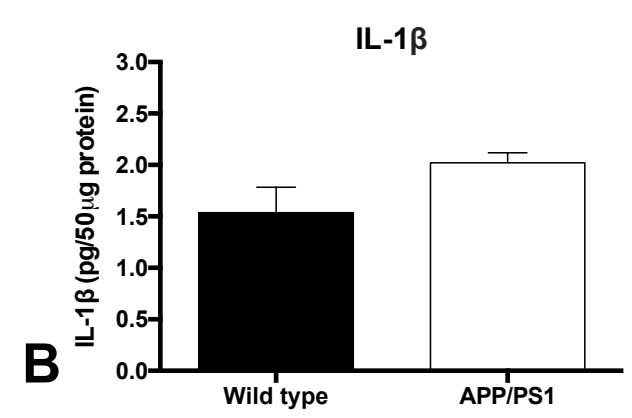

IL-2
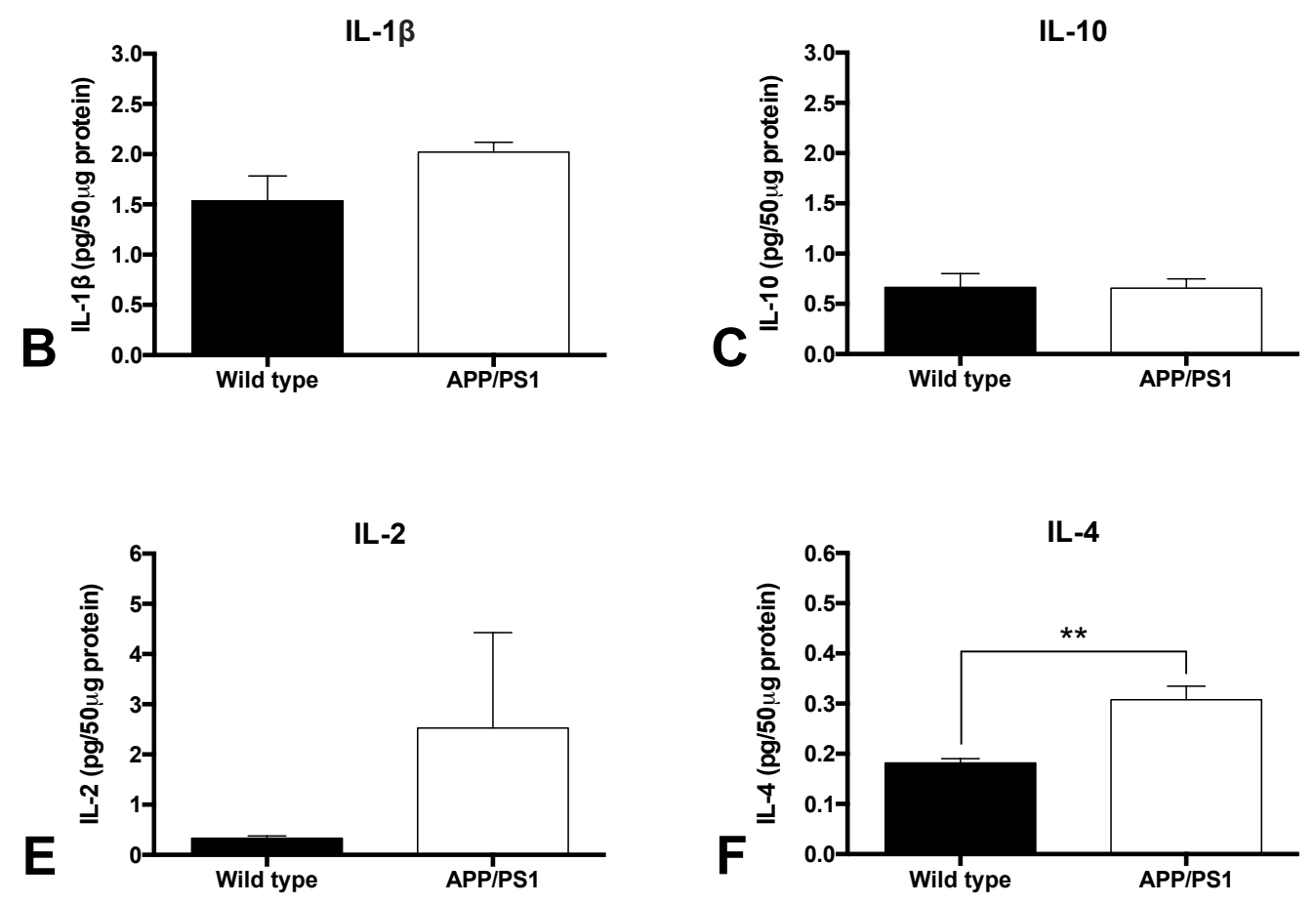
Denver et al. Inflammation, insulin signaling and cognitive function in aged APP/PS1 mice
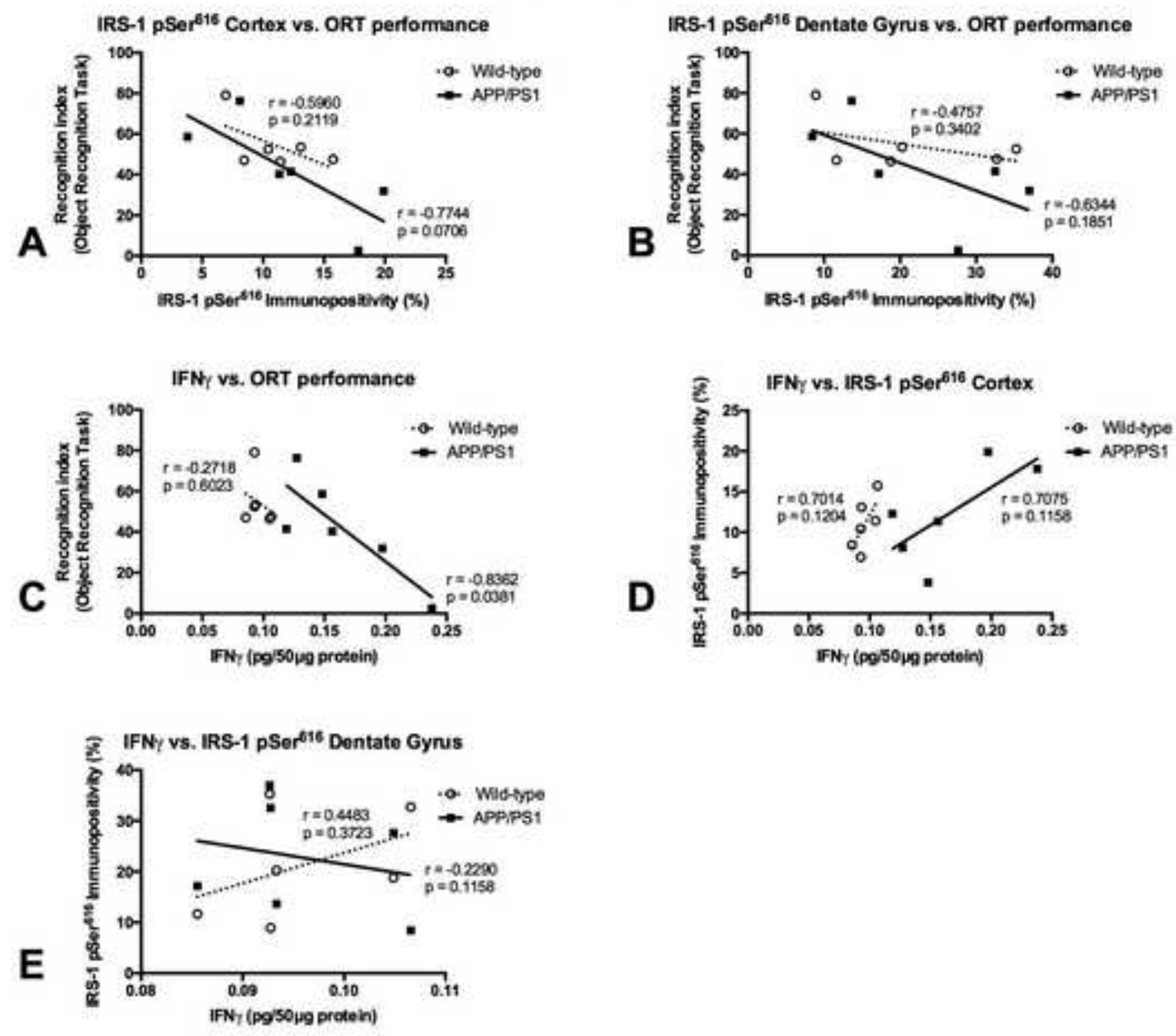
Denver et al. Inflammation, insulin signaling and cognitive function in aged APP/PS1 mice

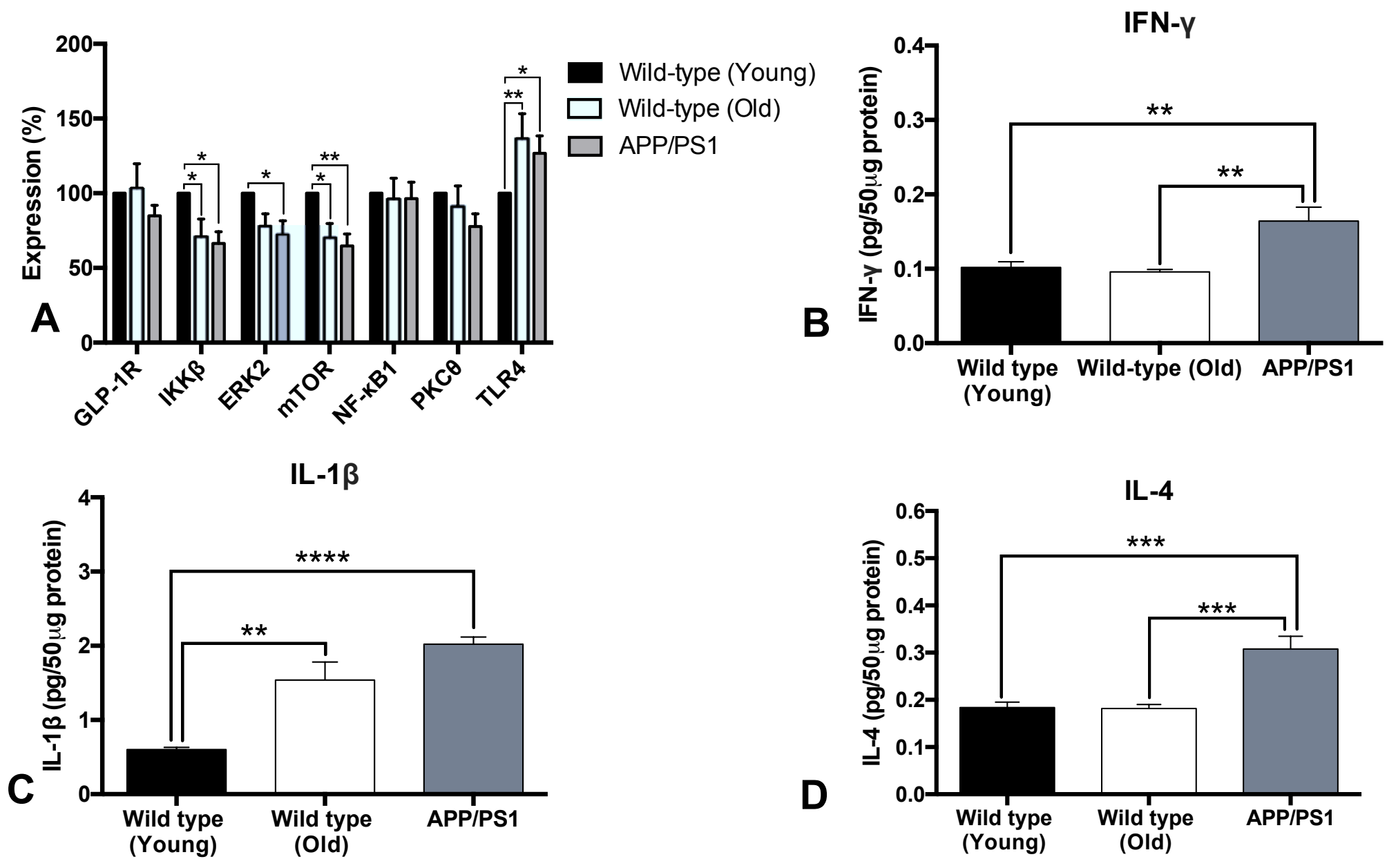




\title{
Inflammation, insulin signaling and cognitive function in aged
}

\section{APP/PS1 mice}

\author{
Paul Denver ${ }^{\mathrm{a}, 1}$, Andrew English ${ }^{\mathrm{b}}$ and Paula L McClean ${ }^{\mathrm{b}}$ \\ ${ }^{a, 1}$ Centre for Molecular Biosciences, University of Ulster, Coleraine, Northern Ireland \\ ${ }^{b}$ Northern Ireland Centre for Stratified Medicine, Clinical, Translational and Research Innovation Centre (C- \\ TRIC), University of Ulster, Derry Londonderry, Northern Ireland
}

Abstract: 287 words

Main text: 4,532 words

Figures: 7

Corresponding author: Paul Denver,

West Los Angeles VA Healthcare Center,

11301 Wilshire Boulevard, Los Angeles, CA 90073

Email address: pdenver@mednet.ucla.edu

Telephone: 1 (310) 478-3711 ext. 42171

${ }^{1}$ Present affiliations: Greater Los Angeles Veterans Affairs Healthcare System; West Los Angeles Medical Center and Dept. of Neurology, University of California, Los Angeles, CA, USA 


\begin{abstract}
Cognitive dysfunction and neuroinflammation are typical in Alzheimer's disease (AD), but are also associated with normal aging, albeit less severely. Insulin resistance in the brain has been demonstrated in $\mathrm{AD}$ patients and is thought to be involved in $\mathrm{AD}$ pathophysiology. Using 15-18 month-old APP/PS1 mice, this study measured peripheral and central insulin signaling and sensitivity, inflammatory markers in brain and plasma and oxidative stress and synapse density in the brain. Novel object recognition, Morris water maze and reversal water maze tasks were performed to assess cognitive function in aged APP/PS1 mice and wild type littermates. Glucose tolerance and insulin sensitivity were similar in APP/PS1 mice and wild type controls, however IRS-1 pSer $^{616}$ was increased in cortex and dentate gyrus of APP/PS1 mice. Recognition and spatial memory was impaired in both APP/PS1 and wild type mice, however learning impairments were apparent in APP/PS1 mice. Expression of GLP-1 receptor, ERK2, IKK $\beta$, mTOR, PKC $\theta, \mathrm{NF}-\mathrm{kB} 1$ and TLR4 was similar between aged APP/PS1 mice and age-matched wild types, however, compared to young wild types (7 9 month-old), IKK $\beta$, mTOR and ERK2 were decreased in brains of APP/PS1 mice, while TLR4 expression was increased.. Compared to age-matched and younger-wild type mice, IFN $\gamma$ and IL-4 were increased in brains of APP/PS1 mice, whereas IL $1 \beta$ was increased in the brains of aged wild type and APP/PS1 mice, compared to young controls.. These results suggest that normal aging may beis associated with enhanced neuroinflammation, oxidative stress, and cognitive decline, however distinctions are apparent in the brain of APP/PS1 mice in terms of inflammation and insulin signaling and in certain cognitive domains. Demarcation
\end{abstract}


of pathological events that distinguish $\mathrm{AD}$ from normal aging will allow for improvements in diagnostic tools and the development of more effective therapeutics.

Keywords: Alzheimer's disease; aging; neuroinflammation; insulin signaling; cognitive function; learning; memory; insulin sensitivity; cytokines

\begin{abstract}
Abbreviations: A $\boldsymbol{\beta}$ Amyloid- $\beta$ AD Alzheimer's disease ERK2 extracellular signal-regulated kinase 2 IKK $\beta$ Inhibitor of NF- $\kappa B$ kinase $\beta$ IRS-1 pSer ${ }^{616}$ Insulin receptor substrate-1 phosphorylated at serine residue 616 MAPK mitogen-activated protein kinase mTOR mechanistic target of rapamycin MWM Morris water maze ORT Novel object recognition task PKC Protein kinase C RI Recognition index RWM Reversal water maze TLR4 Tolllike receptor 4
\end{abstract}

\title{
1 Introduction
}

As healthcare improves around the world, life expectancy continues to rise (1). Accordingly, the past 25 years have seen a dramatic increase in disorders associated with aging, including neurological diseases such as Alzheimer's disease (AD) (1), for which advancing age is the principal risk factor (2).

Many clinical and neuropathological features of AD parallel the normal progression of aging, making differentiation between normal brain aging and early-stage AD difficult. Generally, it can be said that healthy aging is associated with moderate decline in some cognitive abilities, whilst $\mathrm{AD}$ is characterized by severe deterioration of the same cognitive domains, with additional progressive decline of further cognitive functions, such that the patient's daily life is adversely affected to a severe degree (3). In $\mathrm{AD}$, amyloid- $\beta$ ( $\mathrm{A} \beta$ ) accumulates into progressively larger fibrils, which become deposited as insoluble plaques in 
the brain parenchyma (4). Accumulating evidence suggests that the presence of $A \beta$ fibrils and plaques is not uncommon in the brains of non-demented, cognitively healthy older people $(5,6)$. Several studies have also shown that $A \beta$ deposition does not correlate with cognitive impairment in elderly cohorts (6), highlighting the variability of age-related cognitive decline and suggesting that $A \beta$ per se does not directly influence cognitive function.

Profound inflammation is evident in AD brain (7), primarily mediated by microglia and astrocytes $(8,9)$. Activated microglia and astrocytes phagocytose $A \beta$ oligomers and fibrils, degrade $\mathrm{A} \beta$ plaques and reduce amyloid burden $(10,11)$. However, sustained microglial activation and unresolved inflammation in the brain is harmful to neurons and synapses and promotes chronic dysregulation of glial cells and subsequent deterioration of brain structure and function $(12,13)$. Inflammation in the brain increases with age (14) and several studies have shown elevated levels of inflammatory cytokines in the brains of aged rodents $(15,16)$. In the context of $\mathrm{AD}$, primed microglia respond more readily to $\mathrm{A} \beta$, producing increased levels of cytokines that exert direct toxic effects on neurons and at synapses (17).

Insulin resistance has been demonstrated in postmortem brain tissue from AD patients and those with mild cognitive impairment, in the absence of diabetes and irrespective of ApoE- $\varepsilon 4$ status (18). Furthermore, IRS-1 $\mathrm{pSer}^{616}$ was identified as a putative biomarker of brain insulin resistance in $\mathrm{AD}$ and was found to correlate positively with $\mathrm{A} \beta$ oligomer levels and negatively with cognitive function (18). Additionally, Bomfim et al. (19) demonstrated increased levels of IRS-1 pSer ${ }^{616}$ in the hippocampus of 13 month-old APP/PS1 mice. Other studies have also demonstrated impaired neuronal insulin signaling in $\mathrm{AD}$ brain and in response to $A \beta$ oligomer challenge $(20,21)$. 
This study sought to determine differences in learning and memory, oxidative stress, glucose tolerance, central and peripheral insulin sensitivity between 15-18 month old wild type and age-matched APP/PS1 mice. Using novel object recognition and Morris water maze tasks, cognitive function was measured in aged wild type and APP/PS1 mice. Systemic insulin sensitivity and glucose tolerance were compared between groups. Brain levels of $A \beta$, GFAP, 8-oxoguanine, IRS-1 $\mathrm{pSer}^{616}$ and synaptophysin were measured by immunohistochemistry. Additionally inflammatory and insulin signaling associated genes, GLP-1R, IKK $\beta$, ERK2, mTOR, NF-kB1, PKC $\theta$, and TLR4 and inflammatory cytokines (IFN $\gamma$, IL-10, IL-1 $\beta$, IL-12p70, IL-2, IL-4, IL-5, IL-6 and KC/GRO (CXCL1)) were assessed in brain tissue from aged APP/PS1 and wild type mice to delineate pathological changes from those associated with 'normal' aging.

\section{Materials and Methods}

\subsubsection{Animals}

Male $\mathrm{APP}_{\text {swe }} / \mathrm{PS}_{\Delta \mathrm{e} 9}(\mathrm{APP} / \mathrm{PS} 1)$ mice with a C57B1/6J background were bred with wild type C57B1/6J females at the Biomedical and Behavioural Research Unit at Ulster University in Coleraine. Offspring were ear punched and positivity for the $\mathrm{APP}_{\mathrm{swe}} / \mathrm{PS}_{\Delta \mathrm{e} 9}$ transgene, or lack thereof was confirmed by polymerase chain reaction, using primers specific for the APP sequence of the APP/PS1 construct (Forward "GAATTCCGACATGACTCAGG”, Reverse: "GTTCTGCTGCATCTTGGACA"). Offspring males heterozygous for the $\mathrm{APP}_{\mathrm{swe}} / \mathrm{PS}_{\Delta \mathrm{e} 9}$ transgenic construct were then age-matched with wild type littermates, not expressing the 
transgene, which were used as controls. Both groups of mice were caged individually and allowed access to food and water ad libitum. Animals were maintained on a 12:12 light-dark cycle (lights on at 08:00, lights off at 20:00), within a temperature-controlled room ( $\mathrm{T}$ : $21.5^{\circ} \mathrm{C} \pm 1{ }^{\circ} \mathrm{C}$ ). All tests were performed during the light cycle. All experiments were designed, analyzed and reported in accordance with ARRIVE guidelines. Experiments were licensed according to UK Home Office regulations (UK Animals Scientific Procedures Act 1986) and associated guidelines (EU Directive 2010/63/EU). C57Bl/6 mice were derived from a colony maintained in the Biomedical and Behavioural Research Unit at Ulster University in Coleraine.

\subsubsection{Glucose tolerance and insulin sensitivity tests}

After an overnight fasting period, APP/PS1 mice and age-matched wild types received an i.p. injection of glucose $(18 \mathrm{mmol} / \mathrm{kg}$ bw) in $0.9 \% \mathrm{NaCl}$ or insulin $(0.25 \mu \mathrm{M} / \mathrm{g})$. Blood glucose was measured at $0,15,30$ and 60 minutes following glucose or insulin injection using a hand-held Ascencia Contour blood glucose meter (Bayer Health Care).

\subsubsection{Behavioural Assessment}

Mice were assessed in the ORT, as described previously (22). Briefly, mice were subjected to a 10 minute acquisition period, with two identical objects, followed by a 3 hour retention period and a 10 minute test phase, which involved replacing one of the objects with a novel object. A recognition index (RI) was calculated for each object, defined as amount of time spent exploring object A or B over the total time spent exploring both objects $\mathrm{x} 100$ (tA or $\mathrm{tB} /(\mathrm{tA}+\mathrm{tB}) \times 100)$.

Following ORT, mice were assessed in the Morris water maze (MWM) (22). The acquisition training phase consisted of $4 \times 90$ second trials per day, for 4 consecutive days, 
followed by a probe trial on the fifth day. The day after the probe trial, mice were subjected to reversal water maze (RWM), wherein the escape platform was moved from the southwest to northwest quadrant. There were 4 trials per day, for 4 consecutive days, followed by a reversal probe trial on day 5 .

\subsubsection{Immunohistochemistry}

Following sacrifice, animals were perfused with PBS and brains excised. One hemisphere was fixed in 4\% paraformaldehyde and the other was frozen in liquid nitrogen. Hemi-brains for histology were then transferred to $30 \%$ sucrose and $40 \mu \mathrm{m}$ coronal sections were cut using a cryostat (Leica Microsystems). One section in every 6 was collected sequentially and stored at $-20^{\circ} \mathrm{C}$. Staining was performed for A $\beta$, GFAP, 8-oxoguanine, IRS-1 $\mathrm{pSer}^{616}$ and synaptophysin. All sections were incubated in $\mathrm{H}_{2} \mathrm{O}_{2}$ and permeabilized using Triton X. For 8oxoguanine, sections were incubated at $37^{\circ} \mathrm{C}$ for 30 minutes with $2 \mathrm{M}$ hydrochloric acid, followed by $0.1 \mathrm{M}$ borax (Sigma Aldrich) for 10 minutes. Blocking with $1.5 \%-10 \%$ normal serum was performed prior to incubation with anti-A $\beta$ (1:200; Invitrogen; 71-5800) antiGFAP (1:250; Merck Millipore; MAB3402), anti-8-oxoguanine (1:250; Merck Millipore; MAB3560), anti-IRS-1 pSer ${ }^{616}$ (1:200; Invitrogen; 44-550G) or anti-synaptophysin (1:200; Abcam; ab7837) antibodies overnight at $4^{\circ} \mathrm{C}$. Sections were then incubated with secondary antibodies and visualized using Vectastain Elite and SG substrate (Vector Laboratories). Percentage area stained in each image was quantified using a multi threshold plug-in within Image $\mathrm{J}$ (NIH, Bethesda, USA) in a blinded manner.

\subsubsection{Quantitative polymerase chain reaction ( $q P C R$ )}


RNA was extracted from brain tissue using RNeasy Lipid Tissue Mini Kit (Qiagen) according to manufacturer's instructions. For cDNA synthesis, transcriptor First Strand cDNA synthesis kit (Roche Diagnostics) was used using 500 ng of RNA per sample. Realtime PCR reactions were composed of; $5 \mu$ of PCR MasterMix (Roche Diagnostics), $1 \mu \mathrm{l}$ (10 $\mathrm{pM} / \mu \mathrm{l})$ gene-specific probes, $3 \mu \mathrm{l}$ of RNase free water and $1 \mu \mathrm{l}(25 \mathrm{ng})$ of template cDNA. Gene-specific probes (Roche Diagnostics) were as follows: GLP-1R (Glplr), IKK $\beta$ (Ikbkb), ERK2 (Mapk1), mTOR (Mtor), NF-kB1 (Nfkb1), PKC (Prkcq) and TLR4 (Tlr4). Quantitative PCR was performed on Lightcycler 480 system (Roche Diagnostics), and quantified on accompanying software package (Roche, Lightcycler 480 software, v1.5). Gene expression changes were calculated using Delta Delta CT mathematical model (23).

\subsubsection{Meso Scale Discovery multi-array}

Whole hemi-brains were homogenized under liquid nitrogen, followed by addition of $10 \mathrm{ml} / \mathrm{g}$ of lysis buffer (1 mM EDTA in PBS supplemented with protease inhibitor cocktail). Samples were centrifuged at $14,000 \mathrm{G}$ for $20 \mathrm{~min}$ at $4^{\circ} \mathrm{C}$ and supernatant was removed and added to Meso Scale Discovery $\left(\mathrm{MSD}^{\circledR}\right)$ plate. Bradford protein assay was performed to measure protein content and data were normalized to the total amount of protein present in each sample. Levels of IFN $\gamma$, IL1 $\beta$, IL-2, IL-4, IL-5, IL-6, IL-10, IL-12p70, TNF- $\alpha$ and KC/GRO (CXCL1) were quantified in brain and plasma using MSD $^{\circledR}$ Multi-spot Assay Proinflammatory panel 1 kit (Rockville, MD, USA) according to manufacturer's instructions.

\subsubsection{Statistical Analysis}

Data were analyzed using Graphpad Prism (v6.0h). Differences were deemed to be significant if $p \leq 0.05$. Data are expressed as means \pm SEM. Tests included one-way or twoway ANOVA and unpaired Student's $t$ tests. Data heterogenity was tested and, where 
variance was significant, appropriate non-parametric tests were used. Corrections for multiple comparisons were performed using appropriate post-hoc tests. Linear relationships between two variables were measured by Pearson's correlation analysis.

\section{Results}

\subsubsection{Spatial learning is impaired in aged APP/PS1 mice}

During the acquisition phase of the MWM, escape latency significantly decreased over time $(p<0.0001)$, as expected, and was also significantly greater overall in APP/PS1 mice (Fig. $1 \mathrm{~A} ; p=0.0264)$. However, post-hoc analysis indicated that average escape latency was not significantly different between aged wild type and APP/PS1 mice on any of the training days (Fig. 1A). In the probe trial, time spent in each quadrant by wild type mice was not significantly different (Fig. 1D). Similarly, APP/PS1 mice spent a similar amount of time swimming in all 4 quadrants in the probe trial and although significant variation in the time spent in each quadrant was detected $(p=0.0174)$, post-hoc analysis showed that time spent in the target quadrant by APP/PS1 mice was not significantly different from any other quadrant (Fig. 1G). In the acquisition phase of the RWM, escape latency decreased over time (Fig. 1B; $p=0.0009$ ) and was also significantly affected by genotype (Fig. 1B; $p=0.0020$ ). Post-hoc analysis revealed that average escape latency was significantly greater in APP/PS1 mice, compared to wild types on days $2(p<0.05), 3(p<0.01)$ and 4 ( $p<0.05$; Fig. 1B).

In the reversal probe trial, time spent in each of the quadrants by wild types (Fig. 1E) or APP/PS1 (Fig. 1H) mice did not differ significantly

\subsubsection{Recognition memory is impaired in aged APP/PS1 and wild type mice}

In the acquisition phase of the ORT, recognition indices for the identical objects were not significantly different in 15-18 month old APP/PS1 or wild type mice (Fig. 1C). In the test 
phase, recognition index for the novel object was not significantly different from the familiar in the aged APP/PS1 mice or the age-matched control group (Fig. 1F).

\subsubsection{Immunohistochemistry}

\subsubsection{A $\beta$ deposition is ubiquitous in brains of aged APP/PS1 mice}

Representative micrographs from wild type mice show that $A \beta$ immunopositivity was almost completely absent from the cortex $(0.0054 \% \pm 0.0012)$ and dentate gyrus $(0.0178 \pm 0.0136)$ (Fig. 2A and B). However, widespread A $\beta$ deposition was apparent in the cerebral cortex and dentate gyrus of APP/PS1 mice (Fig. $2 \mathrm{E}$ and F). Quantification confirmed that A $\beta$ immunopositivity was significantly higher in the cortex (Fig. 2D; $p<0.0001)$ and dentate gyrus (Fig. $2 \mathrm{H} ; p<0.0001$ ) of APP/PS1 mice compared to wild type controls.

\subsubsection{IRS-1 $p S e r^{616}$ is elevated in brains of aged APP/PS1 mice}

Representative micrographs illustrate increased levels of IRS-1 $\mathrm{pSer}^{616}$ in the cerebral cortex (Fig. 2M) and dentate gyrus (Fig. 2N) of APP/PS1 mice, compared to age-matched wild types (Fig. 2I and J). Although distribution of IRS-1 $\mathrm{pSer}^{616}$ staining was similar between groups in both brain regions, staining intensity was greater in APP/PS1 mice (Fig. 2O) compared to wild types (Fig. 2K). As such, quantification showed that IRS-1 pSer ${ }^{616}$ was significantly greater in the cortex (Fig. $2 \mathrm{~L} ; p=0.0303$ ) and dentate gyrus (Fig. 2P; $p=0.0429$ ) of aged APP/PS1 mice compared to wild type controls. Pearson's correlation analysis identified negative correlations between recognition index for the novel object in ORT and IRS-1 pSer ${ }^{616}$ immunopositivity in the cortex (Fig. 7A) dentate gyrus (Fig. 7B) of wild type and APP/PS1 mice. Although the negative correlation between cortical IRS-1 $\mathrm{pSer}^{616}$ staining 
and ORT recognition index in APP/PS1 approached significance (Fig. 7A; $r=-0.7744$, $p=0.0706$ ) the negative trends between IRS-1 $\mathrm{pSer}^{616}$ staining and ORT recognition index remained insignificant in both brain regions of both genotypes.

\subsubsection{Oxidative stress is comparable in brains of aged APP/PS1 and wild type mice}

Representative micrographs shown in Fig. 3A-C and E-G illustrate the similarity in oxidative stress levels between the brains of aged APP/PS1 mice and wild type controls. Quantitative analysis demonstrated that 8-oxoguanine immunopositivity was not significantly different in the cortex (Fig. 3D) or the dentate gyrus (Fig. 3H) of APP/PS1 mice compared to agematched wild type controls.

\subsubsection{Astrocytes are elevated in brains of aged APP/PS1 mice}

Representative micrographs illustrate increased levels of GFAP-positive astrocytes in the cerebral cortex (Fig. 3I and J) and dentate gyrus (Fig. 3M and N) of aged APP/PS1 mice compared to wild type controls. Quantitative analysis revealed a significant increase in GFAP immunopositivity in the cortex (Fig. 3L; $p=0.0010$ ) and dentate gyrus (Fig. 3P; $p=0.0007$ ), compared to age-matched wild type mice.

3.1.3.5 Synaptophysin is reduced in the polymorphic layer of the dentate gyrus of aged APP/PS1 mice

Representative images illustrate reduced synaptophysin in the hippocampal polymorphic layer of 15-18 month old APP/PS1 mice (Fig. 4D) compared to wild types (Fig. 4A; $p=0.0338$ ). Synaptophysin staining was similar in all other layers of the hippocampus between wild type and APP/PS1 mice and was not significantly different in the granule cell (Fig. 4D), molecular layer (Fig. 4D), strata radiatum (Fig. 4E), pyramidale (Fig. 4E) or oriens 
(Fig. 4E) of APP/PS1 mice, compared to wild type controls (Fig. 4A and B). Furthermore, synaptophysin optical density did not differ significantly in the inner or outer (Fig. 4F) cortical layers of APP/PS1 mice, compared to age-matched wild types (Fig. 4C). Quantification confirmed that synaptophysin staining was reduced in the polymorphic layer of APP/PS1 mice, but was comparable with wild types in all other layers of the hippocampus and cortex (Fig. 4G).

\subsubsection{Peripheral insulin sensitivity and glucose tolerance and inflammatory and insulin} signaling gene expression in brains of aged APP/PS1 mice

Expression of GLP-1R, IKK $\beta$, ERK2, mTOR, NF-кB1, PKC $\theta$ and TLR4 was comparable in brains of aged APP/PS1 and wild type mice and genotype did not have a significant effect on gene expression (Fig. 5A). Additional analysis comparing aged APP/PS1 mice with younger C57B1/6 mice (17-22 weeks old) identified a significant effect of genotype on gene expression (Supplementary Fig. 1A; Fig. 5B; $p<0.0001)$ and post-hoc analysis showed that expression of IKK $\beta(p<0.01)$, ERK2 $(p<0.05)$ and mTOR $(p<0.01)$ was significantly downregulated and TLR4 $(p<0.05)$ was up-regulated in brains of aged APP/PS1 mice, compared to young $\mathrm{C} 57 \mathrm{Bl} / 6$ controls. As illustrated in Fig. $5 \mathrm{C}$, in response to an insulin sensitivity test, a significant decrease in blood glucose over time was detected $(p<0.0001)$, however genotype had no significant effect on blood glucose levels. Similarly, glucose tolerance was comparable in both groups and although time significantly affected blood glucose levels $(p<0.0001)$, genotype was not associated with a change in peripheral glucose tolerance (Fig. 5D). 
Brain levels of IFN $\gamma(p=0.0015$ Fig. 6A; $p=0.0046), I L 1 \beta(p<0.0001)$ and IL-4 ( $p=0.0002$ Fig. $\underline{6 \mathrm{~F} ;} \underline{p=0.0013}$ ) were significantly impacted by genotype (Fig. 6A, C and F). Post-hoc analysis revealed that IFNy was significantly elevated in brains of 15-18 month-old APP/PS1 mice compared to age-matched $(p<0.01)$ and young $(p<0.01)$-wild type mice (Fig. 6A). A trend towards elevated IL-1 $\beta$ was eomparable - detected in the brains of APP/PS1 mice and compared to age-matched wild types, however a significant increase in II $1 \beta$ protein was detected in the brains of APP/PS1 mice, compared to 17-22 week-old wild type micethis $\underline{\text { failed to reach significance (Fig. 6C; } p=\leq 0.0965001 \text { ). FurthermoreAdditional analysis }}$ indicated that, IL-1 $\beta$ was significantly elevated in the brains of 15-18 month-old wild type

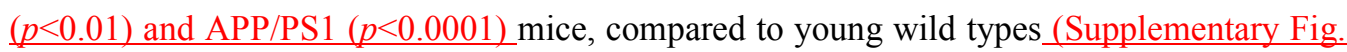
1B) (Fig. 6C; $p<0.01)$. A significant increase in IL-4 (Supplementary Fig. 1C; $p<0.001)$ and IFN $\gamma$ (Supplementary Fig. 1D; $p<0.01$ ) was also detected in the brains of aged APP/PS1 mice, compared to age matched $(p<0.001)$ and-young $(p<0.001)$-wild type mice-(Fig. 6F). In addition, Pearson's correlation analysis identified a significant negative correlation between levels of IFN $\gamma$ and novel object recognition index in APP/PS1 mice (Fig. 7C; $r=-0.8362$, $p=0.0381$ ), suggesting that higher levels of IFN $\gamma$ in the brain were associated with worse ORT performance in APP/PS1 mice. No significant correlations were identified between IFN $\gamma$ and IRS-1 pSer ${ }^{616}$ immunopositivity in the cortex or dentate gyrus (Fig. 7D and E).

\section{Discussion}

This study showed that peripheral glucose tolerance and insulin sensitivity were comparable between aged APP/PS1 and wild type mice, conflicting with a number of other studies (24, 25). It has been suggested that $5 / 6$ hours fasting is optimal for glucose and insulin tolerance tests, as this was sufficient for normalization of glucose levels and phosphorylation of insulin signaling proteins $(26,27)$. The current study performed glucose tolerance and insulin
Formatted: Font: Not Italic

Formatted: Font: Italic

Formatted: Font: Not Italic

Formatted: Font: Italic 
sensitivity tests following an overnight fasting period, so it is possible that results presented here reflect an exaggerated suppression of basal glucose levels in mice as a result of prolonged fasting. This suggestion is supported by Jimenez-Palomares et al. (28) who also found that glucose tolerance and insulin sensitivity were not significantly different in 8 month-old APP/PS1 mice, compared to wild types following overnight fasting periods. Future studies should avoid overnight fasting prior to glucose and insulin tolerance tests in order to achieve optimal normalization of metabolic parameters and to avert potentially dangerous hypoglycemic effects of insulin. Other reports suggest that insulin insensitivity and glucose intolerance also exists in aged animals (29-31), including C57Bl/6 mice (32-34); a possible explanation for the similarity between APP/PS1 mice and controls in the present study. To better understand the impact of central insulin resistance on global insulin utilisation in the APP/PS1 model, future studies should assess the impact of hypothalamic insulin administration alone and in combination with insulin sensitising drugs, such as metformin, in hyperinsulinemic euglycemic clamp models.

Recognition memory was impaired in APP/PS1 mice here, consistent with several other studies (35-37). However, since wild type controls also exhibited impaired recognition memory, the deficits may be related to advanced age, rather than the APP/PS1 genotype; a suggestion supported by other studies reporting recognition memory deficits in aged C57Bl/6 mice $(38,39)$. Another study found several indications of cognitive dysfunction in 18-20 month-old C57Bl/6 mice, including impaired novel location memory, but not object recognition memory (40). Spatial learning was impaired in aged APP/PS1 mice, in agreement with other studies $(41,42)$. Spatial memory recall was impaired in APP/PS1 mice and wild type mice, similar to Barreto et al. (43), who showed that spatial learning and memory were impaired in 18 month-old C57Bl/6 mice. Other reports have highlighted age-related decline in learning and memory in $\mathrm{C} 57 \mathrm{~B} 1 / 6$ mice $(44,45)$ consistent with the findings of the present 
study, providing further evidence that there exists age-related deterioration of cognitive function in $\mathrm{C} 57 \mathrm{~B} 1 / 6$ mice. Learning in the reversal water maze task was impaired in aged APP/PS1 mice, compared to controls, while both APP/PS1 mice and wild types failed to recognize the reversal target quadrant. Some (46), but not others (47) have shown that reversal learning and memory are impaired in APP/PS1 mice. Results presented here, suggest that reversal learning is a cognitive domain that is especially vulnerable to the effects of $\mathrm{AD}$ pathology in aged mice.

Amyloid- $\beta$ (A $\beta$ ) deposits were detected throughout the brains of 15-18 month-old APP/PS1 mice, while A $\beta$ was undetectable in wild type controls. APP/PS1 mice develop plaque deposition by 6 months of age, which progressively worsens, leading to abundant and widespread $A \beta$ plaque pathology by the age of 14 months $(48,49)$. The finding that $A \beta$ deposition was significant in APP/PS1 brains and absent from wild types suggests that the spatial memory deficits in both groups were not directly related to $\mathrm{A} \beta$ burden.

Oxidative stress levels were similar between APP/PS1 and wild type mice in the cortex and dentate gyrus. This was unexpected given previous reports showing elevated oxidative damage in brains of aged APP/PS1 mice (50-52). However, since aging is associated with accumulation of oxidative stress in the brain $(53,54)$, results presented here may reflect age-related accumulation of oxidative DNA damage in both APP/PS1 and wild type mice.

IRS-1 pSer ${ }^{616}$ was increased in brains of APP/PS1 mice, as has also been observed in AD patients $(18,19,55)$ and in experimental models $(55,56)$. The findings of the present study corroborate those of Talbot et al. (18) that demonstrated elevated IRS-1 pSer ${ }^{616}$ in the hippocampus of APP/PS1 mice. IRS-1 $\mathrm{pSer}^{616}$ has been shown to robustly correlate with cognitive impairment and brain insulin resistance associated with $\mathrm{AD}$ (18) and is likely related to the cognitive impairment in APP/PS1 mice here. It is interesting to note that the 
increased brain insulin resistance in aged APP/PS1 mice was apparent in the absence of any significant indications of peripheral insulin insensitivity or glucose intolerance.

Astrocytes were increased in the cortex and dentate gyrus of APP/PS1 mice, consistent with previous reports $(50,57)$. Neuroinflammation and glial cell proliferation, recruitment and activation is a commonly associated with $\mathrm{AD}$ pathology (13). The fact that $\mathrm{A} \beta$ deposition remained substantial in the brains of APP/PS1 mice suggests that clearance of $\mathrm{A} \beta$ was minimal, providing support for the proposal that astrocyte function is defective in AD (58). EAlthough expression of several-inflammatory and insulin signaling genes was similar in brains of aged APP/PS1 mice and age-matched wild type controls., comparison with younger control mice showed that IKK $\beta$, ERK2 and mTOR were reduced, while TLR4 was increased in brains of APP/PS1 mice compared to young wild types. It has been shown previously that expression of TLR4 is up-regulated in brains of APP/PS1 and wild type mice in an age-related manner (59) and the present report provides further evidence that TLR4 expression in brain is increased with normal aging, to levels comparable with APP/PS1 mice. Th1 cytokine IFN $\gamma$ was elevated in brains of APP/PS1 mice compared to young and old-wild types, in agreement with another study that showed age-related enhancement of IFN $\gamma$ in brains of $\mathrm{AD}$ mice from 3 to 19 months of age (60). It has also been shown that IFN $\gamma$ has opposing functions in $\mathrm{AD}$ brain, whereby overexpression of IFN $\gamma$ in the hippocampus augments neuroinflammation and worsens $\mathrm{A} \beta$ burden, but abrogates tau pathology and enhances synaptic markers and neurogenesis (61). Further experimentation should determine whether the increased IFN $\gamma$ in brains of APP/PS1 mice here represents a component of pathogenic neuroinflammation or an up-regulation of protective processes. A significant negative correlation was identified here between IFN $\gamma$ levels and novel object recognition memory in APP/PS1 mice, in line with a recent study demonstrating improved hippocampal synaptic plasticity and cognitive performance in mice deficient for IFN $\gamma(62)$, suggesting that 
increased IFN $\gamma$ in the brain may impair cognitive function in aged APP/PS1 mice. The increase in IFN $\gamma$ is mirrored by a comparable increase in anti-inflammatory IL-4 in brains of APP/PS1 mice, which likely reflects an attempt to suppress the Th1 response. Interestingly IFN $\gamma$ has also been implicated in attenuation of insulin signaling (63) and may be similarly associated with the brain insulin resistance in the present study. Although we failed to detect significant correlations between brain levels of IFN $\gamma$ and IRS-1 $\mathrm{pSer}^{616}$, this potential mechanism certainly warrants further exploration.

Previous studies have detected increased IL-1 $\beta$ in the brains of APP/PS1 mice (64, 65 ) in agreement with the present report. The present report, however, detected a non$\underline{\text { significant trend towards an increase in IL-1 } \beta \text { in the brains of APP/PS1 mice, possibly due to }}$ a parallel, age-related elevation of IL-1 $\beta$ in wild-type mice. It has been demonstrated that $\Lambda \beta$ stimulates IL $1 \beta$ production and secretion via NLRP3 dependent cleavage of pro IL $1 \beta$ by caspase-1 $(66,67)$. It is also interesting to note that IL-1 $\beta$ is the only one of all cytokines measured that was increased in both aged APP/PS1 and wild type mice, compared to young wild types. This suggests that IL-1 $\beta$ is involved with neuroinflammation that accompanies normal aging, while IFN $\gamma$ and IL-4 are not part of the normal process of aging, but are components of the neuroinflammatory processes associated with $\mathrm{AD}$, since these were elevated in aged APP/PS1 mice, compared to both young and old wild types.

Expression of mTOR and ERK2 was reduced-comparable in brains of aged APP/PS1 mice, compared to young wild types. Extracellular signal-regulated kinase 2 (ERK2) signaling facilitates learning and memory $(68,69)$, suggesting that impaired cognitive function in aged mice may be due, in part to reduced expression of ERK2 in the brain. Dineley et al. (70) showed that A $\beta$ reduces ERK2 activity and that ERK2 expression is down-regulated in brains of 20 month-old AD mice, similar to results presented here. Similarly, dysregulation of signaling downstream of mTOR has been demonstrated in post- 
mortem brain tissue from AD patients (71), consistent with the reduced mTOR expression in APP/PS1 brain shown here. Signaling through mTOR contributes to synaptic plasticity, learning and memory $(72,73)$. It has also been shown that insulin promotes neurogenesis, dendrite and synapse formation by signaling through IRS-mediated activation of mTOR (74, 75). Amyloid- $\beta$ (A $\beta$ ) perturbs mTOR signaling in neurons (76) and mTOR inhibition impairs hippocampal LTP in an AD mouse model (77). Our results suggest that expression of insulin signaling components is comparable in aged APP/PS1 and wild-type mice. Disruption of insulin signaling in the brain may be involved in the pathophysiology of AD and may contribute to cognitive impairments associated with aging, a proposition that should be further probed in future studies.

Synaptophysin staining was reduced in the polymorphic layer of the dentate gyrus of APP/PS1 mice. Several previous studies have shown that synapse density is decreased in the brains of APP/PS1 mice (78-80). These studies did not consider the discrete cellular layers of the hippocampus and may have overlooked subtle variation in synapse density between subregions (78-80). However, one report showed that synaptophysin levels in the hippocampus of 7 and 17 month-old APP/PS1 mice were similar to age-matched wild types (81), which more closely aligns with the findings of the present study. It has also been shown in Tg2576 mice, that synaptophysin levels were no different from controls at 3, 9, 14 and 19 months of age (82), while Xu et al. (45) reported age-related decline in hippocampal synaptic spine density in C57B1/6 mice. Results of the present report reflect a similar pattern, with synapse density being comparable to wild types in 15-18 month-old APP/PS1 mice. Since synapse density in the polymorphic layer was reduced in aged transgenic mice, it is reasonable to suggest that this subregion was selectively susceptible to synaptotoxicity associated with AD neuropathology. 
A limitation of the present study is the absence of young cohorts of wild type and APP/PS1 mice. Based on evidence from the literature, it is likely that peripheral insulin sensitivity, cognitive function and synapse density were influenced by aging. Future studies should include groups of young wild type and transgenic mice in order to more robustly characterize the differences between $\mathrm{AD}$ pathology and changes associated with normal aging, throughout the lifecourse. Another limitation of the present report is that cytokines and mRNA were measured in whole hemi-brains, while analysis of immunohistochemistry was performed on brain sections allowing for quantification within discrete brain regions. This means that comparing the results of our biochemical assays with our immunohistochemical data is difficult. Future studies will analyse mRNA and associated proteins and activation states in discrete brain regions to allow for more accurate demarcation of differences between APP/PS1 mice and wild types with regard to insulin signaling dysregulation and inflammation the brain.

Nevertheless, this study has demonstrated memory deficits and neuroinflammation in aged APP/PS1 and wild type mice. Astrocyte accumulation, IL-1 $\beta$ and IRS-1 pSer ${ }^{616}$ levels were increased in the brain of APP/PS1 mice in the absence of systemic insulin insensitivity or glucose intolerance. Pharmacological agents targeting impaired insulin signaling and inflammation in the brain may prove efficacious in treating $\mathrm{AD}$, a suggestion requiring further investigation.

\section{Acknowledgements}

Some of the data has been submitted, in abstract form, to the 2017 Southern California Alzheimer's Disease Centers Research Symposium at the University of California, Beckman Center of the National Academies of Sciences \& Engineering, 100 Academy Way, Irvine, CA, USA 92617 


\title{
Funding
}

This work was supported by the Department of Education and Learning, Northern Ireland.

\section{Declaration / Conflict of Interest}

All authors declare that there is no duality of interest associated with their contribution to this manuscript.

\begin{abstract}
Author Contribution Statement
PMcC conceived the study, participated in the analysis and interpretation of data, drafted the manuscript and revised it critically for intellectual content. PD participated in data generation, analysis and interpretation and drafted the manuscript and revised it critically for intellectual content. AE participated in data generation and analysis. All authors approved the final version of the manuscript. PD is the guarantor of this work and, as such, had full access to all the data in the study and takes responsibility for the integrity of the data and the accuracy of the data analysis.
\end{abstract}

\section{$\underline{\text { References }}$}

1. Global, regional, and national life expectancy, all-cause mortality, and causespecific mortality for 249 causes of death, 1980-2015: a systematic analysis for the Global Burden of Disease Study 2015. Lancet (London, England). 2016;388(10053):1459-544.

2. Querfurth HW, LaFerla FM. Alzheimer's disease. The New England journal of medicine. 2010;362(4):329-44.

3. McKhann GM, Knopman DS, Chertkow H, Hyman BT, Jack CR, Jr., Kawas CH, et al. The diagnosis of dementia due to Alzheimer's disease: recommendations from the National Institute on Aging-Alzheimer's Association workgroups on diagnostic guidelines for Alzheimer's disease. Alzheimer's \& dementia : the journal of the Alzheimer's Association. 2011;7(3):263-9.

4. De-Paula VJ, Radanovic M, Diniz BS, Forlenza OV. Alzheimer's disease. Subcellular biochemistry. 2012;65:329-52. 
5. Savva GM, Wharton SB, Ince PG, Forster G, Matthews FE, Brayne C. Age, neuropathology, and dementia. The New England journal of medicine. 2009;360(22):2302-9.

6. Malek-Ahmadi M, Perez SE, Chen K, Mufson EJ. Neuritic and Diffuse Plaque Associations with Memory in Non-Cognitively Impaired Elderly. Journal of Alzheimer's disease : JAD. 2016;53(4):1641-52.

7. Meraz-Rios MA, Toral-Rios D, Franco-Bocanegra D, Villeda-Hernandez J, CamposPena V. Inflammatory process in Alzheimer's Disease. Front Integr Neurosci. 2013;7:59.

8. Rezai-Zadeh K, Gate D, Town T. CNS infiltration of peripheral immune cells: DDay for neurodegenerative disease? Journal of neuroimmune pharmacology : the official journal of the Society on NeuroImmune Pharmacology. 2009;4(4):462-75.

9. Schilling M, Besselmann M, Leonhard C, Mueller M, Ringelstein EB, Kiefer R. Microglial activation precedes and predominates over macrophage infiltration in transient focal cerebral ischemia: a study in green fluorescent protein transgenic bone marrow chimeric mice. Experimental neurology. 2003;183(1):25-33.

10. Fu Y, Hsiao JT, Paxinos G, Halliday GM, Kim WS. ABCA7 Mediates Phagocytic Clearance of Amyloid-beta in the Brain. Journal of Alzheimer's disease : JAD. 2016;54(2):569-84.

11. El-Shimy IA, Heikal OA, Hamdi N. Minocycline attenuates Abeta oligomersinduced pro-inflammatory phenotype in primary microglia while enhancing Abeta fibrils phagocytosis. Neuroscience letters. 2015;609:36-41.

12. Leszek J, Barreto GE, Gasiorowski K, Koutsouraki E, Avila-Rodrigues M, Aliev G. Inflammatory Mechanisms and Oxidative Stress as Key Factors Responsible for Progression of Neurodegeneration: Role of Brain Innate Immune System. CNS \& neurological disorders drug targets. 2016;15(3):329-36.

13. Steardo L, Jr., Bronzuoli MR, Iacomino A, Esposito G, Steardo L, Scuderi C. Does neuroinflammation turn on the flame in Alzheimer's disease? Focus on astrocytes. Frontiers in neuroscience. 2015;9:259.

14. Gabuzda D, Yankner BA. Physiology: Inflammation links ageing to the brain. Nature. 2013;497(7448):197-8.

15. Maher FO, Martin DS, Lynch MA. Increased IL-1beta in cortex of aged rats is accompanied by downregulation of ERK and PI-3 kinase. Neurobiology of aging. 2004;25(6):795-806.

16. Godbout JP, Chen J, Abraham J, Richwine AF, Berg BM, Kelley KW, et al. Exaggerated neuroinflammation and sickness behavior in aged mice following activation of the peripheral innate immune system. FASEB journal : official publication of the Federation of American Societies for Experimental Biology. 2005;19(10):132931.

17. Hong S, Beja-Glasser VF, Nfonoyim BM, Frouin A, Li S, Ramakrishnan S, et al. Complement and microglia mediate early synapse loss in Alzheimer mouse models. Science (New York, NY). 2016;352(6286):712-6.

18. Talbot K, Wang HY, Kazi H, Han LY, Bakshi KP, Stucky A, et al. Demonstrated brain insulin resistance in Alzheimer's disease patients is associated with IGF-1 resistance, IRS-1 dysregulation, and cognitive decline. The Journal of clinical investigation. 2012;122(4):1316-38.

19. Bomfim TR, Forny-Germano L, Sathler LB, Brito-Moreira J, Houzel JC, Decker H, et al. An anti-diabetes agent protects the mouse brain from defective insulin signaling caused by Alzheimer's disease- associated Abeta oligomers. The Journal of clinical investigation. 2012;122(4):1339-53. 
20. Moloney AM, Griffin RJ, Timmons S, O'Connor R, Ravid R, O'Neill C. Defects in IGF-1 receptor, insulin receptor and IRS-1/2 in Alzheimer's disease indicate possible resistance to IGF-1 and insulin signalling. Neurobiology of aging. 2010;31(2):224-43.

21. Liu Y, Liu F, Grundke-Iqbal I, Iqbal K, Gong CX. Deficient brain insulin signalling pathway in Alzheimer's disease and diabetes. The Journal of pathology. 2011;225(1):54-62.

22. McClean PL, Parthsarathy V, Faivre E, Holscher C. The diabetes drug liraglutide prevents degenerative processes in a mouse model of Alzheimer's disease. The Journal of neuroscience : the official journal of the Society for Neuroscience. 2011;31(17):658794.

23. Livak KJ, Schmittgen TD. Analysis of relative gene expression data using realtime quantitative PCR and the 2(-Delta Delta C(T)) Method. Methods (San Diego, Calif). 2001;25(4):402-8.

24. Clarke JR, Lyra ESNM, Figueiredo CP, Frozza RL, Ledo JH, Beckman D, et al. Alzheimer-associated Abeta oligomers impact the central nervous system to induce peripheral metabolic deregulation. EMBO molecular medicine. 2015;7(2):190-210.

25. Pedros I, Petrov D, Allgaier M, Sureda F, Barroso E, Beas-Zarate C, et al. Early alterations in energy metabolism in the hippocampus of APPswe/PS1dE9 mouse model of Alzheimer's disease. Biochimica et biophysica acta. 2014;1842(9):1556-66.

26. Andrikopoulos S, Blair AR, Deluca N, Fam BC, Proietto J. Evaluating the glucose tolerance test in mice. American journal of physiology Endocrinology and metabolism. 2008;295(6):E1323-32.

27. Agouni A, Owen C, Czopek A, Mody N, Delibegovic M. In vivo differential effects of fasting, re-feeding, insulin and insulin stimulation time course on insulin signaling pathway components in peripheral tissues. Biochemical and biophysical research communications. 2010;401(1):104-11.

28. Jimenez-Palomares M, Ramos-Rodriguez JJ, Lopez-Acosta JF, Pacheco-Herrero M, Lechuga-Sancho AM, Perdomo G, et al. Increased Abeta production prompts the onset of glucose intolerance and insulin resistance. American journal of physiology Endocrinology and metabolism. 2012;302(11):E1373-80.

29. Catalano KJ, Bergman RN, Ader M. Increased susceptibility to insulin resistance associated with abdominal obesity in aging rats. Obesity research. 2005;13(1):11-20.

30. Yamamoto M, Otsuki M. Effect of inhibition of alpha-glucosidase on age-related glucose intolerance and pancreatic atrophy in rats. Metabolism: clinical and experimental. 2006;55(4):533-40.

31. Romanatto T, Fiamoncini J, Wang B, Curi R, Kang JX. Elevated tissue omega-3 fatty acid status prevents age-related glucose intolerance in fat-1 transgenic mice. Biochimica et biophysica acta. 2014;1842(2):186-91.

32. Houtkooper RH, Argmann C, Houten SM, Canto C, Jeninga EH, Andreux PA, et al. The metabolic footprint of aging in mice. Scientific reports. 2011;1:134.

33. Lipina C, Vaanholt LM, Davidova A, Mitchell SE, Storey-Gordon E, Hambly C, et al. CB1 receptor blockade counters age-induced insulin resistance and metabolic dysfunction. Aging cell. 2016;15(2):325-35.

34. Park D, Lee EK, Jang EJ, Jeong HO, Kim BC, Ha YM, et al. Identification of the dichotomous role of age-related LCK in calorie restriction revealed by integrative analysis of cDNA microarray and interactome. Age (Dordrecht, Netherlands). 2013;35(4):1045-60. 
35. Gu XH, Xu LJ, Liu ZQ, Wei B, Yang YJ, Xu GG, et al. The flavonoid baicalein rescues synaptic plasticity and memory deficits in a mouse model of Alzheimer's disease. Behavioural brain research. 2016;311:309-21.

36. Yang YJ, Zhao Y, Yu B, Xu GG, Wang W, Zhan JQ, et al. GluN2B-containing NMDA receptors contribute to the beneficial effects of hydrogen sulfide on cognitive and synaptic plasticity deficits in APP/PS1 transgenic mice. Neuroscience. 2016;335:170-83. 37. Zhou D, Liu H, Li C, Wang F, Shi Y, Liu L, et al. Atorvastatin ameliorates cognitive impairment, Abeta1-42 production and Tau hyperphosphorylation in APP/PS1 transgenic mice. Metabolic brain disease. 2016;31(3):693-703.

38. Qiu J, Dunbar DR, Noble J, Cairns C, Carter R, Kelly V, et al. Decreased Npas4 and Arc mRNA Levels in the Hippocampus of Aged Memory-Impaired Wild-Type But Not Memory Preserved 11beta-HSD1 Deficient Mice. Journal of neuroendocrinology. 2016;28(1).

39. Mechan AO, Wyss A, Rieger H, Mohajeri MH. A comparison of learning and memory characteristics of young and middle-aged wild-type mice in the IntelliCage. Journal of neuroscience methods. 2009;180(1):43-51.

40. Benice TS, Rizk A, Kohama S, Pfankuch T, Raber J. Sex-differences in age-related cognitive decline in C57BL/6J mice associated with increased brain microtubuleassociated protein 2 and synaptophysin immunoreactivity. Neuroscience. 2006;137(2):413-23.

41. Fol R, Braudeau J, Ludewig S, Abel T, Weyer SW, Roederer JP, et al. Viral gene transfer of APPsalpha rescues synaptic failure in an Alzheimer's disease mouse model. Acta neuropathologica. 2016;131(2):247-66.

42. Xiao Q, Shi R, Yang W, Zou Y, Du Y, Zhang M, et al. Time-Dependent Increase of Chitinase1 in APP/PS1 Double Transgenic Mice. Neurochemical research. 2016;41(7):1604-11.

43. Barreto G, Huang TT, Giffard RG. Age-related defects in sensorimotor activity, spatial learning, and memory in C57BL/6 mice. Journal of neurosurgical anesthesiology. 2010;22(3):214-9.

44. Shoji H, Takao K, Hattori S, Miyakawa T. Age-related changes in behavior in C57BL/6J mice from young adulthood to middle age. Molecular brain. 2016;9:11.

45. $\mathrm{Xu} \mathrm{B,} \mathrm{Sun} \mathrm{A,} \mathrm{He} \mathrm{Y,} \mathrm{Qian} \mathrm{F,} \mathrm{Liu} \mathrm{L,} \mathrm{Chen} \mathrm{Y,} \mathrm{et} \mathrm{al.} \mathrm{Running-induced} \mathrm{memory}$ enhancement correlates with the preservation of thin spines in the hippocampal area CA1 of old C57BL/6 mice. Neurobiology of aging. 2017;52:106-16.

46. Cheng D, Low JK, Logge W, Garner B, Karl T. Novel behavioural characteristics of female APPSwe/PS1DeltaE9 double transgenic mice. Behavioural brain research. 2014;260:111-8.

47. O'Leary TP, Brown RE. Visuo-spatial learning and memory deficits on the Barnes maze in the 16-month-old APPswe/PS1dE9 mouse model of Alzheimer's disease. Behavioural brain research. 2009;201(1):120-7.

48. Gallagher JJ, Minogue AM, Lynch MA. Impaired performance of female APP/PS1 mice in the Morris water maze is coupled with increased Abeta accumulation and microglial activation. Neuro-degenerative diseases. 2013;11(1):33-41.

49. McManus RM, Higgins SC, Mills KH, Lynch MA. Respiratory infection promotes T cell infiltration and amyloid-beta deposition in APP/PS1 mice. Neurobiology of aging. 2014;35(1):109-21.

50. Duffy AM, Holscher C. The incretin analogue D-Ala2GIP reduces plaque load, astrogliosis and oxidative stress in an APP/PS1 mouse model of Alzheimer's disease. Neuroscience. 2013;228:294-300. 
51. Jin JL, Liou AK, Shi Y, Yin KL, Chen L, Li LL, et al. CART treatment improves memory and synaptic structure in APP/PS1 mice. Scientific reports. 2015;5:10224.

52. Yun HM, Jin P, Park KR, Hwang J, Jeong HS, Kim EC, et al. Thiacremonone Potentiates Anti-Oxidant Effects to Improve Memory Dysfunction in an APP/PS1 Transgenic Mice Model. Molecular neurobiology. 2016;53(4):2409-20.

53. Chakrabarti S, Munshi S, Banerjee K, Thakurta IG, Sinha M, Bagh MB. Mitochondrial Dysfunction during Brain Aging: Role of Oxidative Stress and Modulation by Antioxidant Supplementation. Aging and disease. 2011;2(3):242-56.

54. Manczak M, Jung Y, Park BS, Partovi D, Reddy PH. Time-course of mitochondrial gene expressions in mice brains: implications for mitochondrial dysfunction, oxidative damage, and cytochrome $c$ in aging. Journal of neurochemistry. 2005;92(3):494-504.

55. Yarchoan M, Toledo JB, Lee EB, Arvanitakis Z, Kazi H, Han LY, et al. Abnormal serine phosphorylation of insulin receptor substrate 1 is associated with tau pathology in Alzheimer's disease and tauopathies. Acta neuropathologica. 2014;128(5):679-89.

56. Zhang B, Tang XC, Zhang HY. Alternations of central insulin-like growth factor-1 sensitivity in APP/PS1 transgenic mice and neuronal models. Journal of neuroscience research. 2013;91(5):717-25.

57. Galea E, Morrison W, Hudry E, Arbel-Ornath M, Bacskai BJ, Gomez-Isla T, et al. Topological analyses in APP/PS1 mice reveal that astrocytes do not migrate to amyloidbeta plaques. Proceedings of the National Academy of Sciences of the United States of America. 2015;112(51):15556-61.

58. Mulder SD, Veerhuis R, Blankenstein MA, Nielsen HM. The effect of amyloid associated proteins on the expression of genes involved in amyloid-beta clearance by adult human astrocytes. Experimental neurology. 2012;233(1):373-9.

59. Lopez-Gonzalez I, Schluter A, Aso E, Garcia-Esparcia P, Ansoleaga B, F LL, et al. Neuroinflammatory signals in Alzheimer disease and APP/PS1 transgenic mice: correlations with plaques, tangles, and oligomeric species. Journal of neuropathology and experimental neurology. 2015;74(4):319-44.

60. Abbas N, Bednar I, Mix E, Marie S, Paterson D, Ljungberg A, et al. Up-regulation of the inflammatory cytokines IFN-gamma and IL-12 and down-regulation of IL-4 in cerebral cortex regions of APP(SWE) transgenic mice. Journal of neuroimmunology. 2002;126(1-2):50-7.

61. Mastrangelo MA, Sudol KL, Narrow WC, Bowers WJ. Interferon-\{gamma\} differentially affects Alzheimer's disease pathologies and induces neurogenesis in triple transgenic-AD mice. The American journal of pathology. 2009;175(5):2076-88.

62. Monteiro S, Ferreira FM, Pinto V, Roque S, Morais M, de Sa-Calcada D, et al. Absence of IFNgamma promotes hippocampal plasticity and enhances cognitive performance. Translational psychiatry. 2016;6:e707.

63. McGillicuddy FC, Chiquoine EH, Hinkle CC, Kim RJ, Shah R, Roche HM, et al. Interferon gamma attenuates insulin signaling, lipid storage, and differentiation in human adipocytes via activation of the JAK/STAT pathway. The Journal of biological chemistry. 2009;284(46):31936-44.

64. Xuan AG, Pan XB, Wei P, Ji WD, Zhang WJ, Liu JH, et al. Valproic acid alleviates memory deficits and attenuates amyloid-beta deposition in transgenic mouse model of Alzheimer's disease. Molecular neurobiology. 2015;51(1):300-12.

65. Guo HB, Cheng YF, Wu JG, Wang CM, Wang HT, Zhang C, et al. Donepezil improves learning and memory deficits in APP/PS1 mice by inhibition of microglial activation. Neuroscience. 2015;290:530-42. 
66. Salminen A, Ojala J, Suuronen T, Kaarniranta K, Kauppinen A. Amyloid-beta oligomers set fire to inflammasomes and induce Alzheimer's pathology. Journal of cellular and molecular medicine. 2008;12(6a):2255-62.

67. Heneka MT, Kummer MP, Stutz A, Delekate A, Schwartz S, Vieira-Saecker A, et al. NLRP3 is activated in Alzheimer's disease and contributes to pathology in APP/PS1 mice. Nature. 2013;493(7434):674-8.

68. Thomas GM, Huganir RL. MAPK cascade signalling and synaptic plasticity. Nature reviews Neuroscience. 2004;5(3):173-83.

69. Satoh Y, Endo S, Ikeda T, Yamada K, Ito M, Kuroki M, et al. Extracellular signalregulated kinase 2 (ERK2) knockdown mice show deficits in long-term memory; ERK2 has a specific function in learning and memory. The Journal of neuroscience : the official journal of the Society for Neuroscience. 2007;27(40):10765-76.

70. Dineley KT, Westerman M, Bui D, Bell K, Ashe KH, Sweatt JD. Beta-amyloid activates the mitogen-activated protein kinase cascade via hippocampal alpha7 nicotinic acetylcholine receptors: In vitro and in vivo mechanisms related to Alzheimer's disease. The Journal of neuroscience : the official journal of the Society for Neuroscience. 2001;21(12):4125-33.

71. Yates SC, Zafar A, Hubbard P, Nagy S, Durant S, Bicknell R, et al. Dysfunction of the mTOR pathway is a risk factor for Alzheimer's disease. Acta neuropathologica communications. 2013;1:3.

72. Sosanya NM, Cacheaux LP, Workman ER, Niere F, Perrone-Bizzozero NI, RaabGraham KF. Mammalian Target of Rapamycin (mTOR) Tagging Promotes Dendritic Branch Variability through the Capture of Ca2+/Calmodulin-dependent Protein Kinase II alpha (CaMKIIalpha) mRNAs by the RNA-binding Protein HuD. The Journal of biological chemistry. 2015;290(26):16357-71.

73. Garza-Lombo C, Gonsebatt ME. Mammalian Target of Rapamycin: Its Role in Early Neural Development and in Adult and Aged Brain Function. Frontiers in cellular neuroscience. 2016;10:157.

74. Lee CC, Huang CC, Hsu KS. Insulin promotes dendritic spine and synapse formation by the PI3K/Akt/mTOR and Rac1 signaling pathways. Neuropharmacology. 2011;61(4):867-79.

75. Zhang J, Ji F, Liu Y, Lei X, Li H, Ji G, et al. Ezh2 regulates adult hippocampal neurogenesis and memory. The Journal of neuroscience : the official journal of the Society for Neuroscience. 2014;34(15):5184-99.

76. Chen TJ, Wang DC, Chen SS. Amyloid-beta interrupts the PI3K-Akt-mTOR signaling pathway that could be involved in brain-derived neurotrophic factor-induced Arc expression in rat cortical neurons. Journal of neuroscience research. 2009;87(10):2297-307.

77. Ma T, Hoeffer CA, Capetillo-Zarate E, Yu F, Wong H, Lin MT, et al. Dysregulation of the mTOR pathway mediates impairment of synaptic plasticity in a mouse model of Alzheimer's disease. PloS one. 2010;5(9).

78. Liu SJ, Yang C, Zhang Y, Su RY, Chen JL, Jiao MM, et al. Neuroprotective effect of beta-asarone against Alzheimer's disease: regulation of synaptic plasticity by increased expression of SYP and GluR1. Drug design, development and therapy. 2016;10:1461-9. 79. Ostapchenko VG, Chen M, Guzman MS, Xie YF, Lavine N, Fan J, et al. The Transient Receptor Potential Melastatin 2 (TRPM2) Channel Contributes to beta-Amyloid Oligomer-Related Neurotoxicity and Memory Impairment. The Journal of neuroscience : the official journal of the Society for Neuroscience. 2015;35(45):15157-69. 
80. Zhang Y, Huang LJ, Shi S, Xu SF, Wang XL, Peng Y. L-3-n-butylphthalide Rescues Hippocampal Synaptic Failure and Attenuates Neuropathology in Aged APP/PS1 Mouse Model of Alzheimer's Disease. CNS neuroscience \& therapeutics. 2016.

81. Minkeviciene R, Ihalainen J, Malm T, Matilainen O, Keksa-Goldsteine V, Goldsteins G, et al. Age-related decrease in stimulated glutamate release and vesicular glutamate transporters in APP/PS1 transgenic and wild-type mice. Journal of neurochemistry. 2008;105(3):584-94.

82. King DL, Arendash GW. Maintained synaptophysin immunoreactivity in Tg2576 transgenic mice during aging: correlations with cognitive impairment. Brain research. 2002;926(1-2):58-68.

\section{Figure Legends}

Figure 1. Learning and memory in aged APP/PS1 and wild type mice. The acquisition training phase of the Morris water maze (MWM) involved four training sessions per day over four consecutive days, followed by a probe trial on the fifth day, 24 hours following the final training session. Escape latency during the training phase is shown (A), as is the proportion of time spent in each quadrant during the probe trial by $15-18$ month-old wild type (solid line with circles; D) and APP/PS1 (dotted line with squares; G) mice. Reversal water maze acquisition training began 24 hours following the MWM probe trial and consisted of four consecutive days with four training sessions per day, followed by a reversal probe trial on the fifth day. Illustrated are training phase escape latency $(\mathbf{B})$ and time spent in each quadrant during the reversal probe trial by wild type $(\mathbf{E})$ and APP/PS1 (H) mice. For the novel object recognition task, recognition index, a measure of the percentage of time spent exploring either object, is illustrated in the acquisition phase $(\mathbf{C})$ during exposure to two identical objects, and the test phase $(\mathbf{F})$, in the presence of one familiar (black bars) and one novel (white bars) object. ${ }^{*} p<0.05, * * p<0.01$ APP/PS1 vs. wild type; - Data represent mean \pm SEM for $13-15$ mice per group, two-way repeated measures ANOVA with Bonferroni's post-hoc test (A, B), ordinary one-way ANOVA with Dunnett's post-hoc test $(\mathbf{D}, \mathbf{E}, \mathbf{G}, \mathbf{H})$, multiple $t$ tests with Holm-Š́dák's post-hoc test $(\mathbf{C}, \mathbf{F})$. Data represent mean \pm $\underline{\text { SEM for 13-15 mice per group. }}$ 
Figure 2. A $\beta$ deposition and IRS-1 pSer $^{616}$ in the cerebral cortex and dentate gyrus of aged APP/PS1 and wild type mice. Representative images (10x magnification) are shown that depict $A \beta$ staining in the cerebral cortex (A) and dentate gyrus (B) of 15-18 month old wild type mice and the cerebral cortex $(\mathbf{E})$ and dentate gyrus $(\mathbf{F})$ of age-matched APP/PS1 mice. Also shown is an exemplary magnified image (20x magnification) of $A \beta$ staining in brains of wild type $(\mathbf{C})$ and APP/PS1 $(\mathbf{G})$ mice. Quantification of A $\beta$ immunopositivity in the cortex (D) and dentate gyrus (H) of 15-18 month old APP/PS1 and wild type mice is also shown. Representative images (20x magnification) are also shown that depict IRS-1 pSer ${ }^{616}$ staining in the cerebral cortex (I) and dentate gyrus (J) of 15-18 month old wild type mice and the cerebral cortex (M) and dentate gyrus (N) of age-matched APP/PS1 mice. Also shown are exemplary magnified images (40x magnification) from wild type $(\mathbf{K})$ and APP/PS1 (O) mice. Quantification of IRS-1 pSer $^{616}$ immunopositivity in cortex (L) and dentate gyrus (P) of 15-18 month old APP/PS1 and wild type mice is also illustrated. ${ }^{*} p<0.05, * * * * p<0.0001$, Student's $t$ test. Data represent mean \pm SEM for 6 per group.

Figure 3. Oxidative stress and astrocytes in the cerebral cortex and dentate gyrus of aged APP/PS1 and wild type mice. Representative images (20x magnification) are shown that depict the 8-oxoguanine staining in cerebral cortex (A) and dentate gyrus (B) of 15-18 month old wild type mice and cerebral cortex (E) and dentate gyrus (F) of age-matched APP/PS1 mice. Also shown are exemplary magnified images (40x magnification) from wild type (C) and APP/PS1 (G) mice. Quantification of 8-oxoguanine immunopositivity in cortex (D) and dentate gyrus (H) of 15-18 month old APP/PS1 and wild type mice is also illustrated. Representative images (20x magnification) are also shown that depict GFAP staining in the cerebral cortex (I) and dentate gyrus (J) of 15-18 month-old wild type mice 
and the cerebral cortex $(\mathbf{M})$ and dentate gyrus $(\mathbf{N})$ of age-matched APP/PS1 mice. Also shown are exemplary magnified images (100x magnification) from wild type (K) and APP/PS1 (O) mice. Quantification of GFAP immunopositivity in cortex (L) and dentate gyrus (P) of 15-18 month old APP/PS1 and wild type mice is also shown. ${ }^{* * *} p<0.001_{2}$; Student's $t$ test. Data represent mean \pm SEM for 6 per group.

Figure 4. Synapse density is decreased in the polymorphic layer of the dentate gyrus in APP/PS1 mice. Illustrated are representative images depicting synaptophysin staining of brain sections from 15-18 month-old wild type (A, B, C) and APP/PS1 (D, E, F) mice. A and $\mathbf{D}$ show the polymorphic layer (PL), granule cell layer (GCL) and molecular layer (ML) of the dentate gyrus. $\mathbf{C}$ and $\mathbf{D}$ show the stratum radiatum (SR), stratum pyramidale (SP) and stratum oriens (SO) of the hippocampus, while $\mathbf{B}$ and $\mathbf{E}$ show the inner (IC) and outer (OC) cerebral cortex. Also illustrated is quantification of synaptophysin optical density values for the polymorphic layer, granule cell layer and molecular layer of the dentate gyrus and the stratum radiatum, stratum pyramidale and stratum oriens of the hippocampus, inner and outer cortex of 15-18 month-old APP/PS1 and wild type mice (G). ${ }^{*} p<0.05_{i ;}$; Student's $t$ tests. Data represent mean \pm SEM for 6 per group.

Figure 5. Peripheral insulin sensitivity, glucose tolerance and expression of inflammatory and insulin signaling genes in brains of aged APP/PS1 mice. Illustrated is quantification of the expression of genes associated with inflammatory pathways and insulin signaling in brains of 15-18 month-old APP/PS1 mice (black bars), compared with agematched wild type controls (white bars) (A). Also shown is quantification of expression of the same genes in aged APP/PS1 and wild type mice, compared with 17-22 week-old wild types (dark grey bars) (B).Also shown are blood glucose levels following insulin injection 
$(\underline{B} \mathbf{C})$ and following glucose injection ( $\underline{\mathbf{C}} \mathbf{B})$. Wild type (solid line with circles) and APP/PS1 mice (dotted line with squares) aged 15-18 months were administered insulin or glucose via i.p. injection and blood glucose levels were measured at 15,30 and 60 minutes post-injection. ${ }^{*} p<0.05,{ }^{*} p<0.01$. Data represent mean \pm SEM for 5 per grot; $\mathrm{p}$, ordinary two-way ANOVA with Holm-Š́ídák's post-hoc test $(\mathbf{A}, \mathbf{B})$ or 13-15 per group, two-way repeated measures ANOVA with Holm-Š́ídák's post-hoc test $(\underline{\mathbf{B}} \mathbf{C}, \underline{\mathbf{C}} \boldsymbol{B})$. Data represent mean $\pm \mathrm{SEM}$ for 5 per group.

Figure 6. Cytokine levels in the brains of aged APP/PS1 and wild type mice. MSD multiplex analysis of 8 cytokines was performed on supernatant extracted from brain tissue. Protein levels of IFN $\gamma(\mathbf{A})$, IL-10 (B), IL-1 $\beta$ (C), IL-12p70 (D), IL-2 (E), IL-4 (F), IL-5 (E), IL-6 (G) and KC/GRO (CXCL1) (H) were measured and compared between 15-18 monthold APP/PS1 mice (black bars) and; age-matched wild types (white bars). and younger mice, aged 1722 weeks (dark grey bars). ${ }^{* *} p<0.01$; Student's $t$ tests.,$* * * p<0.001$, **** $<0.0001$. Data represent mean \pm SEM for 6 per group,, ordinary one way ANOVA with Holm-Š́dák's post hoc test.

Figure 7. Correlations between IFN $\gamma$, IRS-1 pSer $^{616}$ and novel object recognition memory in aged APP/PS1 and wild type mice. Pearson's correlation analysis was performed between IRS-1 pSer $^{616}$ immunopositivity and novel object recognition index (A, B), between IFN $\gamma$ and novel object recognition index (C) and between IFN $\gamma$ and IRS-1 pSer ${ }^{616}$ immunopositivity (D, E) in wild type (open circles and dotted best fit line) and APP/PS1 (black squares and solid best fit line) mice. Lines of best fit, $r$ and $p$ values were also added to the graphs. Each data point represents an $X Y$ pair for a total of $6 X Y$ pairs per genotype on each graph. Significance of correlation was determined using two-tailed $t$ tests. 
Supplementary Figure 1. Cytokines and gene expression in brains of young wild type mice. Quantification of expression of inflammatory and insulin signaling genes in the brains of young wild type mice (17-22 weeks old), is shown (black bars), compared to aged wild types (white bars), and APP/PS1 mice (dark grey bars).(A). Also illustrated are brain levels of IFN $y$ (B), IL-1 $\beta$ (C) and IL-4 (D) in young wild type mice, compared with aged wild types and APP/PS1 mice. $* p<0.05, * * p<0.01, * * * p<0.001, * * * * p<0.0001$; ordinary one-way ANOVA with Holm-Š́dák's post-hoc test (A) and Student's $t$ test (B-D). Data represent $\underline{\text { mean } \pm \text { SEM for } 5(\mathrm{~A}) \text { or } 6(\mathbf{B}-\mathbf{D}) \text { per group. }}$ 